\title{
Syntheses of Cyanophycin Segments for Investigations of Cell-Penetration
}

\author{
Marcel Grogg§ \\ Donald Hilvert \\ Albert K. Beck \\ Dieter Seebach* \\ Laboratorium für Organische Chemie (LOC), Departement \\ Chemie und Angewandte, Biowissenschaften (D-CHAB), \\ ETH-Zürich, Hönggerberg HCl, Vladimir-Prelog-Weg 3, 8093 Zürich, \\ Switzerland \\ seebach@org.chem.ethz.ch \\ $\S$ This author did all the experiments \\ Published as part of the 50 Years SYNTHESIS - Golden Anniversary Issue
}

Received: 15.06 .2018

Accepted: 15.06 .2018

Published online: 28.06 .2018

DOI: 10.1055/s-0037-1610202; Art ID: ss-2018-z0415-op

License terms: CCO

Abstract Novel guanidinium-rich oligopeptide derivatives $\mathrm{R}-[\mathrm{Adp}(\mathrm{X})]_{8}-\mathrm{NH}_{2}$ are described, which consist of an octa-aspartic acid backbone with argininylated side chains that are derived from the biopolymer cyanophycin $\left[\mathrm{H}-(\mathrm{Adp})_{\mathrm{n}}-\mathrm{OH}\right]$. The Fmoc-Adp (X,Pbf)-OH building blocks for solidstate peptide synthesis (SSPS) of Adp octamers were prepared from Fmoc-Arg(Pbf)-OH and Fmoc-Asp-OAll. Coupling on PAL resin provided four octamers with and without $\mathrm{N}$-terminal fluorescent groups (FAM) and C-terminal amide groups. Milligram quantities of Adp-octamers were isolated after preparative HPLC purification. The structure of the novel guanidinium-rich oligomers is unique insofar as the side chains of the $\mathrm{Asp}_{8}$-backbone include both a guanidino and a carboxylic acid group, the influence of which will be tested with the corresponding ester and amide derivatives that were synthesized in parallel. Unusual cellpenetrating properties of the Adp-octamers are expected.

Key words guanidinium-rich oligopeptides, $\beta^{3} / \alpha$-Asp-Arg-dipeptide building block, biopolymer cyanophycin, solid-state peptide synthesis, cell-penetrating peptides

Arginine- and lysine-rich natural $\left(\mathrm{Tat}^{1}{ }^{1}\right.$ Penetratin ${ }^{2}$ ) and unnatural peptides (oligo-arginines and other guanidinium-rich compounds $)^{3,4}$ are cell-penetrating peptides (CPPs) and can carry a large variety of cargoes into prokaryotic and eukaryotic cells. ${ }^{3-5}$ A schematic representation is shown in Figure $1 \mathbf{A}$; the number of guanidinium groups is usually between 4 and 14 . For a more detailed discussion and additional literature, see the citations in references ${ }^{3-5}$ and in the introduction of our recent paper on cell penetration, herbicidal activity, and in vivo toxicity of guanidinium-rich compounds. ${ }^{6}$

Despite all the activity in this field there has been no attention paid by the CPP community, so far, to the biopolymer cyanophycin (Figure $1 \mathbf{B}$ ), a guanidinium-rich natural

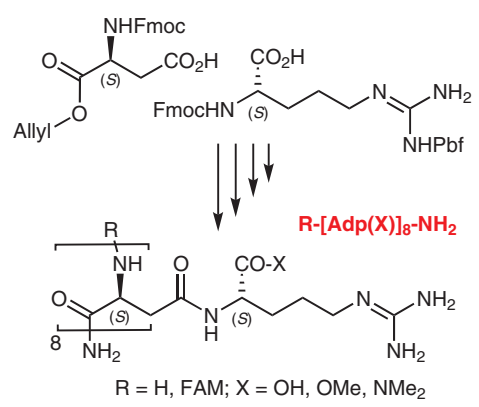

A

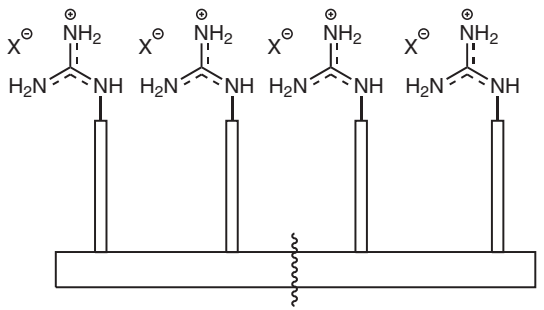

B

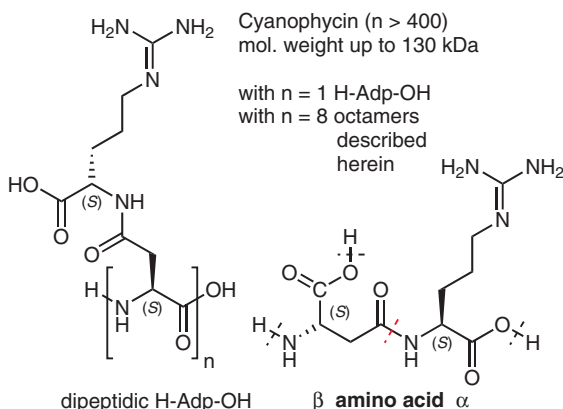

Figure 1 Schematic representation $\mathbf{A}$ of a common guanidinium-rich system and formulae $\mathbf{B}$ of cyanophycin, its building block $\mathrm{H}-\mathrm{Adp}-\mathrm{OH}$, and the octamers described herein (with $\mathrm{C}$-terminal $\mathrm{NH}_{2}$ )

product, which was discovered in characteristic granules in blue-green algae by the Italian botanist Antonio Borzi in 1887 and chemically identified by R. D. Simon in $1971 .^{7}$ In recent years, the biopolymer cyanophycin, a temporary microbial nitrogen storage material of cyanobacteria, has been studied most comprehensively by the group of $A$. Steinbüchel. ${ }^{8,9}$ The polymer and its dipeptidic building block can be produced using industrial equipment 'on any desired scale'. ${ }^{\text {a }}$ Cyanophycin is a polyaspartic acid argininylated on the carboxylic acid groups of the side-chains, and the building block is a dipeptide with aspartic acid incorporated as a $\beta^{3}$ amino $\operatorname{acid}^{10}$ (Figure $1 \mathbf{B}$ ). For simplicity, we use the threeletter code Adp for the cyanophycin building block. ${ }^{6}$ Since 


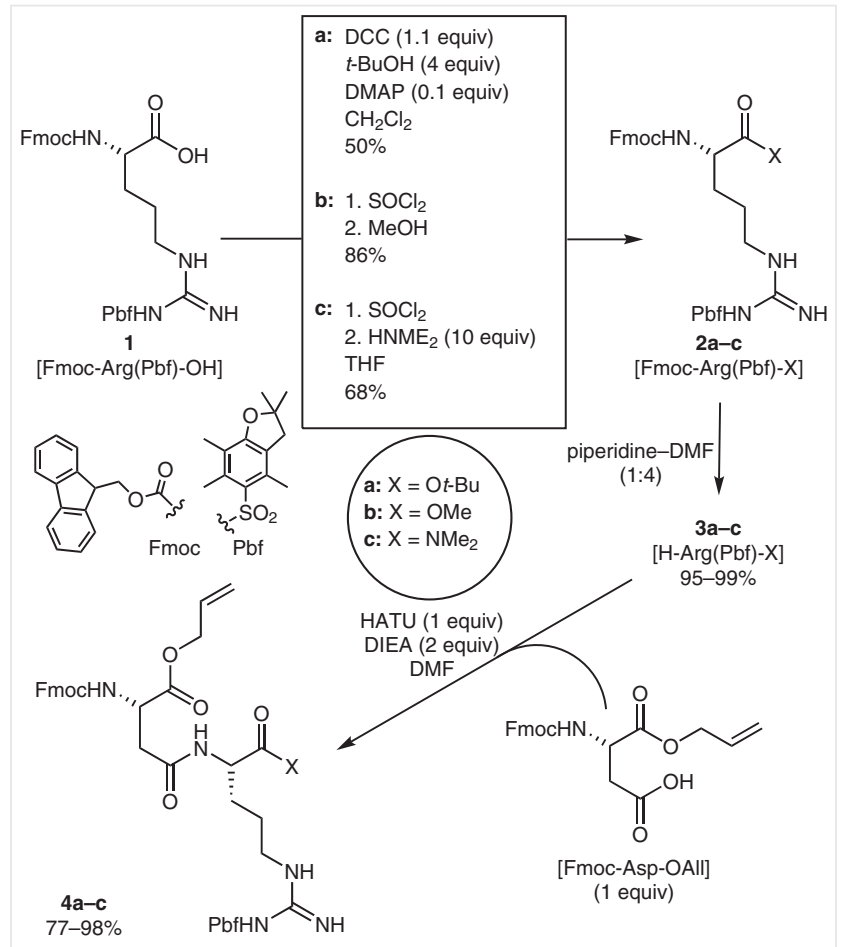

Scheme 1 Connecting arginine with aspartic acid, using the orthogonal protecting groups Pbf, Fmoc, and Allyl, to form the Adp-derivatives 4

peptides with an $\mathrm{N}$-terminal $\beta^{3}$-amino acid residue are not cleaved by common aminopeptidases, ${ }^{10-12}$ H-Adp-OH should be quite stable under physiological conditions.

To be able to find out whether cyanophycin segments with a length typical of CPPs (vide supra) ${ }^{3-5}$ have cell penetrating properties we decided to synthesize octamer derivatives (cf. Figure $1 \mathbf{B}$, with $\mathrm{n}=8$ ) by conventional solid-state peptide synthesis (SSPS) using Fmoc chemistry.

For this purpose, the readily available dipeptide H-Adp$\mathrm{OH}$ (Figure 2) looked like a convenient starting material, but this would have required its modification by selectively (!) protecting the guanidino and the carboxylic acid group in the Arg-residue and by putting an Fmoc group on the N-terminus of the Asp residue. Instead, we synthesized suitably protected dipeptide derivatives $\mathbf{4}$ from the commercially available compounds, Fmoc-Arg(Pbf)-OH (1) and FmocAsp-OAll, as outlined in Scheme 1.

The carboxylic acid group of the protected arginine 1 was activated with dicyclohexylcarbodiimide or with thionyl chloride, followed by reactions with $t-\mathrm{BuOH}, \mathrm{MeOH}$, or $\mathrm{Me}_{2} \mathrm{NH}$ to give the protected arginine esters $\mathbf{2 a}$ and $\mathbf{2 b}$, and amide 2c, respectively, in yields ranging from ca. 50 to $86 \%$. Removal of the Fmoc group provided the Arg derivatives $\mathbf{3}$ with free amino groups, to which the Asp moiety was attached by reaction with Fmoc-Asp-OAllyl under peptidecoupling conditions to produce the three Fmoc-Adp(Pbf,X)-

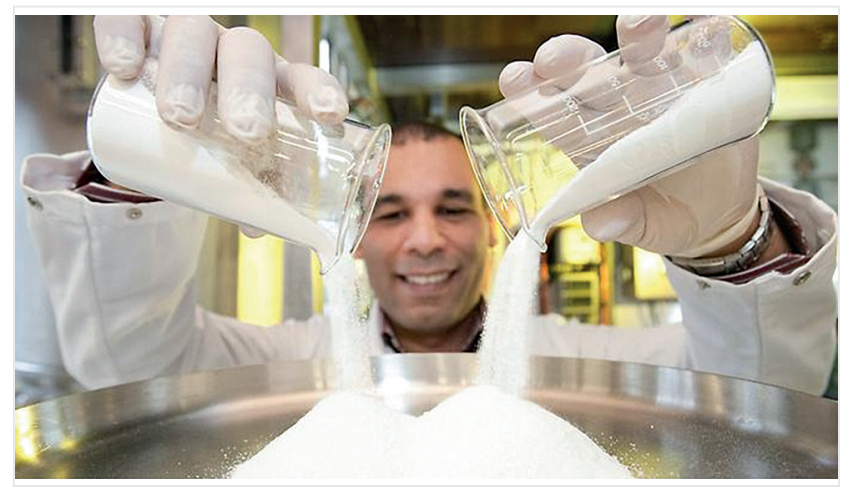

Figure 2 Readily available dipeptide $\mathrm{H}$-Adp-OH ${ }^{9}$ [with permission of A. Sallam (Cysal GmbH, Technologiehof Münster) and of dpa]

OAllyl derivatives 4a-c. De-allylation with phenylsilane/ $\mathrm{Pd}\left(\mathrm{PPh}_{3}\right)_{4}$ led to the building blocks Fmoc-Adp(Ot-Bu,Pbf)-OH (5), Fmoc-Adp(OMe,Pbf)-OH (6), and Fmoc$\mathrm{Adp}\left(\mathrm{NMe}_{2}, \mathrm{Pbf}\right)-\mathrm{OH}(\mathbf{7})$, ready for SSPS (see Scheme 2). Overall yields of up to $40 \%$ could be attained for the four steps from Fmoc-Arg(Pbf)-OH (1) to the Adp building blocks 5-7 (for details, see Experimental part). Compound 5 with a $t$-Bu ester group was actually prepared as precursor to Adp-octamers 8a and $\mathbf{b}$ with free carboxylic acid groups, formed concomitantly with removal of the peptide from the resin by trifluoroacetic acid (TFA).

As resin for the SSPS we used N-alkylated PAL, ${ }^{13}$ the Fmoc-groups of the growing chains were removed with piperidine in DMF, and the couplings were achieved with HATU/Hünig base (DIPEA) in DMF. The same conditions were employed for attachment of the N-terminal fluorescent FAM label (Scheme 3). Release of the peptide chains from the resin and removal of the Pbf protecting groups was performed with TFA- $\mathrm{H}_{2} \mathrm{O}-\mathrm{TIS}$, and the products were purified by preparative HPLC. Milligram amounts of the octa-Adp-carboxamides 8-10 (Schemes 2, 3) were synthesized in this way.

We also prepared the octa-Adp-amides with methyl ester $\mathbf{9}$ and amide groups $\mathbf{1 0}$ in the side chains in order to be able to compare the biological activities of Adp-octamers with and without a possible internal neutralization of positively charged guanidinium by negatively charged carboxylate groups (see $\mathbf{8} \mathbf{a}$ and $\mathbf{b}$ and formulae in Figure $1 \mathbf{B}$ ).

The determination of i.v. toxicities and the cell-penetrating properties of octa-Adp derivatives described herein are reported in ref. ${ }^{6}$ and will be described in a separate paper, ${ }^{14}$ respectively.

Protected amino acids and the PAL resin were purchased from Bachem, HATU from Aapptec, 5(6)-carboxyfluorescein (5/6-FAM) from abcr and all other chemicals were purchased from Sigma Aldrich. All reagents were used as received, solvents were technical grade, and the reactions were run in open flasks fitted with PFTE 


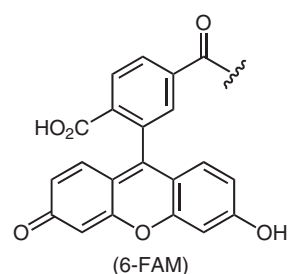<smiles>O=C(O)c1ccc(-c2c3ccc(=O)cc-3oc3cc(O)ccc23)c(C(=O)O)c1</smiles><smiles>CC(C)(C)C(=O)c1ccc(C(=O)O)c(-c2c3ccc(=O)cc-3oc3cc(O)ccc23)c1</smiles><smiles>[X]C(=O)[C@H](CCCN=C(N)N)NC(=O)C[C@H](NC(C)=O)C(N)=O</smiles>

8a: $\mathrm{X}=\mathrm{OH}, \mathrm{R}=\mathrm{H}$ $\left\{\mathrm{H}-[\mathrm{Adp}(\mathrm{OH})]_{8}-\mathrm{NH}_{2}\right\}$

8b: $\mathrm{X}=\mathrm{OH}, \mathrm{R}=\mathrm{FAM}$ \{FAM- $[\mathrm{Adp}(\mathrm{OH})]_{8}-\mathrm{NH}_{2}$ \}

9a: $\mathrm{X}=\mathrm{OMe}_{2}, \mathrm{R}=\mathrm{H}$ $\left\{\mathrm{H}-[\mathrm{Adp}(\mathrm{OMe})]_{8}-\mathrm{NH}_{2}\right\}$

9b: $\mathrm{X}=\mathrm{OMe}_{2}, \mathrm{R}=\mathrm{FAM}$ [FAM-[Adp (OMe) $]_{8}-\mathrm{NH}_{2}$

10a: $\mathrm{X}=\mathrm{NMe}_{2}, \mathrm{R}=\mathrm{H}$ $\left\{\mathrm{H}-\left[\operatorname{Adp}\left(\mathrm{NMe}_{2}\right)\right]_{8}-\mathrm{NH}_{2}\right\}$ 10b: $\mathrm{X}=\mathrm{NMe}_{2}, \mathrm{R}=\mathrm{FAM}$ $\left.\left\{\text { FAM-[Adp }\left(\mathrm{NMe}_{2}\right)\right]_{8}-\mathrm{NH}_{2}\right\}$

Scheme 2 Deallylation of 4a-c to give the SSPS-building blocks Fmoc-Adp(X,Pbf)-OH 5-7 for assembly to the target octa-Adp derivatives without (8a, $\mathbf{9 a}$, and $\mathbf{1 0 a}$ ) and with (8b, 9b, and 10b) a FAM fluorescence label

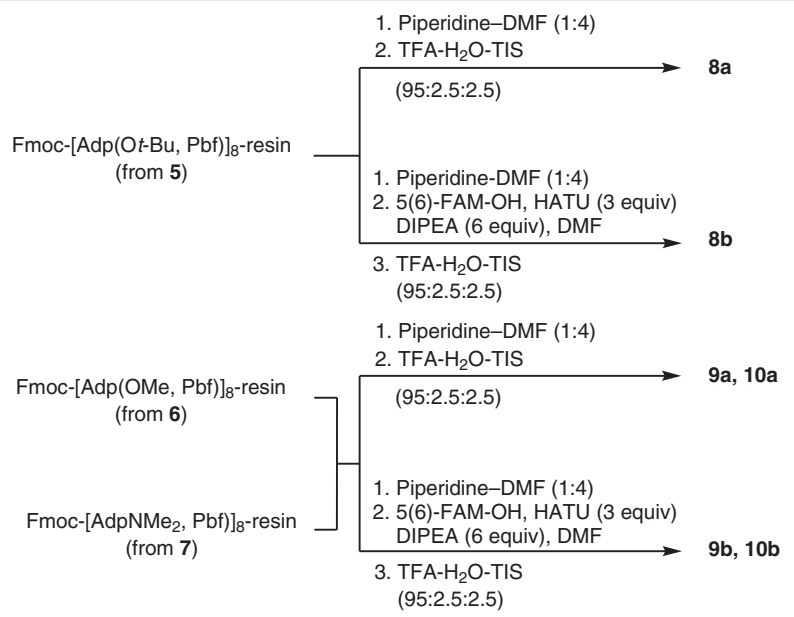

$$
\begin{aligned}
& \text { PAL resin }
\end{aligned}
$$

Scheme 3 Assemblies of 8 Adp-building blocks by SSPS on PAL resin (Bachem, 200-400 mesh, $0.28 \mathrm{mmol} / \mathrm{g}$ ) to give the octamers 8-10 with C-terminal amide groups on milligram scale. TIS: Triisopropylsilane. coated magnetic stir bars at r.t., unless otherwise noted. Peptide couplings were carried out in ISOLUTE ${ }^{\circledR}$ Double fritted filtration column, $15 \mathrm{~mL} 20 \mu \mathrm{m}$ PE (reaction vessel, Biotage) at r.t. The building blocks for peptide synthesis were activated in $4 \mathrm{~mL}$ screw vial $45 \times 14.77$ mm (activation vessel, BGB) closed with PFTE lined cap 13-425 (Thermo Scientific) at r.t. Analytical TLC was performed with Merck 60 F254 pre-coated aluminum silica plates and visualized by UV detection $(254 \mathrm{~nm})$. Flash column chromatography (FC) was performed using SiliCycle (SilaFlash ${ }^{\circledR}$ P60, 230-400 mesh particle size) silica gel. All fractions collected by FC were analyzed by TLC to identify the different compounds. Melting points were recorded on a Büchi melting point B-540 device.

IR spectra were recorded on a PerkinElmer Spectrum Two FT-IR spectrometer at r.t. using ATR as the sampling technique. NMR spectra were recorded on a Bruker Advance-III $400 \mathrm{MHz}$ spectrometer in the NMR Service at the Laboratory of Organic Chemistry (LOC), ETH Zurich. ${ }^{1} \mathrm{H}$ NMR spectra were recorded relative to the residual solvent peak $\left(\mathrm{CDCl}_{3} \delta_{\mathrm{H}}=7.26\right.$, DMSO- $\left.d_{6} \delta_{\mathrm{H}}=2.50\right)$ and reported as follows: chemical shift (ppm), multiplicity (standard abbreviations; ovlp: overlap), coupling constant $(\mathrm{Hz})$, and integration. ${ }^{13} \mathrm{C}$ NMR spectra were recorded relative to residual solvent peaks $\left(\mathrm{CDCl}_{3} \delta_{\mathrm{C}}=77.0\right.$, DMSO- $d_{6} \delta_{C}=39.5$ ). All ${ }^{1} \mathrm{H}$ and ${ }^{13} \mathrm{C}$ signals were assigned via HSQC and HMBC experiments. ${ }^{19} \mathrm{~F} \mathrm{NMR}\left(\mathrm{D}_{2} \mathrm{O}\right)$ spectra were recorded with ${ }^{1} \mathrm{H}$ decoupling.

The LCMS runs were performed with a Waters Acquity UPLC system equipped with an $\mathrm{H}$-class quaternary solvent manager, an $\mathrm{H}$-class sample manager FTN with sample organizer, a PDA detector, a SQ detector 2, and a $1.7 \mu \mathrm{m} 2.1 \times 50 \mathrm{~mm}$ BEM C18 UPLC column. Eluent system: $\mathrm{H}_{2} \mathrm{O}$ and $\mathrm{MeCN}$ containing $0.1 \% \mathrm{HCO}_{2} \mathrm{H}$ using a flow of $1 \mathrm{~mL} / \mathrm{min}$ 
(Gradient: 0-0.2 min, 5\% MeCN; 0.2-1.5 min, 5-80\% MeCN; $1.5-2$ min, $80-100 \%$, MeCN; $2-2.2$ min, $100 \%$ MeCN; $2.2-2.3$ min, $100-5 \%$ $\mathrm{MeCN}$; $2.3-3$ min, $5 \% \mathrm{MeCN})$.

All semi-preparative HPLC runs were performed with a Waters preparative 150 LC system equipped with a 2545 quaternary gradient module, a 2489 UV/visible detector, a Fraction Colector III and $5 \mu \mathrm{m}$ $20 \times 150$ mm Reprosil-pure 120 C18 AQ column (Dr. Maisch GmBH, Basel, Switzerland). Eluent system: $\mathrm{H}_{2} \mathrm{O}$ and $\mathrm{MeCN}$ containing $0.1 \%$ TFA, using a flow of $10 \mathrm{~mL} / \mathrm{min}$ (Gradient 1: 0-5 min, 30\% MeCN; 570, 30-90\% MeCN; 70-75 min, 90\% MeCN. Gradient 2: 0-5 min, 10\% MeCN; 5-45 min, 10-90\% MeCN; 45-55 min, 90\% MeCN).

All analytical HPLC runs were performed with a Dionex Ultimate 3000 system equipped with a 3000 pump module, a 3000 Autosampler, a 3000 RS Variable Wavelength Detector, and a $3.5 \mu \mathrm{m} 4.6 \times 150$ mm XBridge $\mathrm{C} 18$ column. Eluent system: $\mathrm{H}_{2} \mathrm{O}$ and $\mathrm{MeCN}$ added with $0.1 \%$ TFA, using a flow of $1 \mathrm{~mL} / \mathrm{min}$ (Gradient: $0-1 \mathrm{~min}, 5 \% \mathrm{MeCN}$; $1-$ 16 min, 5-50\% MeCN; 16-19 min, 50\% MeCN; 19-20 min, 50-95\% MeCN; 20-23 min, 95\% MeCN).

All self-measured MALDI-TOF were recorded on a Brucker microflex benchtop MALDI-TOF system. High-resolution mass spectrometry (HRMS) was performed on a Bruker maXis UHR-TOF by electrospray ionization (ESI) or a Bruker solariX by matrix-assisted laser desorption/ionization (MALDI) by the Molecular and Biomolecular Analysis Service (MoBiAS) of the LOC at ETH Zurich. MoBiAS also performed elemental analysis.

\section{Preparation of Building Block 5}

\section{tert-Butyl $N^{2}-\{[(9 H-F l u o r e n-9-y l) m e t h o x y]$ carbonyl $\}-N^{\omega}$ - [(2,2,4,6,7-pentamethyl-2,3-dihydrobenzofuran-5-yl)sulfonyl]ar- gininate (2a)}

In a $100 \mathrm{~mL}$ round-bottomed flask, Fmoc-Arg(Pbf)-OH (6.0 g, 9.25 mmol) and DMAP ( $119.4 \mathrm{mg}, 977 \mu \mathrm{mol}, 0.11$ equiv) were dissolved in $\mathrm{CH}_{2} \mathrm{Cl}_{2}(20 \mathrm{~mL}$ ). Then, $t$-BuOH ( $4 \mathrm{~mL}, 41.82 \mathrm{mmol}, 4.52$ equiv) was added and the flask was cooled for 5 min on ice. To the cooled mixture, DCC ( $2.11 \mathrm{~g}, 10.23 \mathrm{mmol}, 1.11$ equiv) was added and the resulting solution was stirred for further 5 min on ice. Afterwards, the flask was left with stirring for $3 \mathrm{~h} 40 \mathrm{~min}$ at r.t. The reaction mixture was then poured into $1 \mathrm{M}$ aq $\mathrm{HCl}(20 \mathrm{~mL})$ and extracted with $\mathrm{CH}_{2} \mathrm{Cl}_{2}(2 \times$ $40 \mathrm{~mL})$. The organic layers were combined and dried $\left(\mathrm{MgSO}_{4}\right)$ before being evaporated in vacuo. The crude product was purified by FC (EtOAc- $\mathrm{CH}_{2} \mathrm{Cl}_{2}, 1: 1$ ). All collected fractions were analyzed by TLC, combined, and evaporated to give compound $2 \mathrm{a}$ in $50 \%$ yield $(3.25 \mathrm{~g}$, $4.61 \mathrm{mmol}$ ) as a colorless powder; $R_{\mathrm{f}}=0.54$ (EtOAc- $\left.\mathrm{CH}_{2} \mathrm{Cl}_{2}, 1: 1\right)$.

${ }^{1} \mathrm{H}$ NMR $\left(400 \mathrm{MHz}, \mathrm{CDCl}_{3}\right): \delta=7.75(\mathrm{dt}, J=7.5,1.0 \mathrm{~Hz}, 2 \mathrm{H}$, Fmoc $\mathrm{CH}_{\mathrm{AR}}$ ), 7.60-7.49 (m, $2 \mathrm{H}, \mathrm{Fmoc} \mathrm{CH}_{\mathrm{AR}}$ ), 7.42-7.34 (m, $2 \mathrm{H}, \mathrm{Fmoc} \mathrm{CH}_{\mathrm{AR}}$ ), 7.29 (ddd, $\left.J=7.4,4.0,1.2 \mathrm{~Hz}, 2 \mathrm{H}, \mathrm{Fmoc} \mathrm{CH}_{\mathrm{AR}}\right), 6.14$ (s, $1 \mathrm{H}, \mathrm{Gua} \mathrm{NH}$ ), 6.08 (s, $2 \mathrm{H}$, Gua NH), 5.55 (d, $J=8.1 \mathrm{~Hz}, 1 \mathrm{H}, \mathrm{NH}$ amide), 4.37 (d, $J=$ $7.1 \mathrm{~Hz}, 2 \mathrm{H}$, Fmoc $\mathrm{CH}_{2}$ ), 4.18 (t ovlp, J $=7.0 \mathrm{~Hz}, 2 \mathrm{H}, \mathrm{Fmoc} \mathrm{CH}+\mathrm{Arg} \alpha$ $\mathrm{CH}$ ), 3.35-3.05 (m, $\left.2 \mathrm{H}, \operatorname{Arg} \mathrm{CH}_{2}\right), 2.91(\mathrm{~s}, 2 \mathrm{H}, \mathrm{Pbf} \mathrm{CH}$ ), $2.58(\mathrm{~s}, 3 \mathrm{H}$, Pbf $\left.\mathrm{CH}_{3}\right), 2.51$ (s, $\left.3 \mathrm{H}, \mathrm{Pbf} \mathrm{CH}_{3}\right), 2.07$ (s, $\left.3 \mathrm{H}, \mathrm{Pbf} \mathrm{CH}_{3}\right), 1.87-1.64(\mathrm{~m}, 2$ $\left.\mathrm{H}, \operatorname{Arg} \mathrm{CH}_{2}\right), 1.64-1.53\left(\mathrm{~m}, 2 \mathrm{H}, \operatorname{Arg} \mathrm{CH}_{2}\right), 1.45\left(\mathrm{~s}, 9 \mathrm{H}, t-\mathrm{C}_{4} \mathrm{H}_{9}\right), 1.43(\mathrm{~s}, 6$ $\left.\mathrm{H}, 2 \times \mathrm{Pbf} \mathrm{CH}_{3}\right) ;($ EtOAc and traces DCC).

${ }^{13} \mathrm{C}$ NMR (101 MHz, $\mathrm{CDCl}_{3}$ ): $\delta=171.35$ ( $\mathrm{C}=\mathrm{O} t$-Bu ester), 158.91 ( $\mathrm{Pbf}$ $\left.{ }_{A R} C-O\right), 156.62$ (Fmoc $C=0$ ), 156.12 (Gua $\left.C=N\right), 143.85$ (Fmoc ${ }_{A R} C=C$ ), 143.72 (Fmoc ${ }_{A R} C=C$ ), 141.43 (Fmoc ${ }_{A R} C=C$ ), 141.41 (Fmoc ${ }_{A R} C=C$ ), $138.58\left(\mathrm{Pbf}{ }_{A R} \mathrm{C}=\mathrm{C}\right), 132.96\left(\mathrm{Pbf}{ }_{A R} \mathrm{C}=\mathrm{C}\right), 132.52\left(\mathrm{Pbf}{ }_{A R} \mathrm{C}=\mathrm{C}\right), 127.93$ (Fmoc ${ }_{A R} \mathrm{C}=\mathrm{C}$ ), 127.90 (Fmoc ${ }_{A R} \mathrm{C}=\mathrm{C}$ ), 127.25 (Fmoc ${ }_{A R} \mathrm{C}=\mathrm{C}$ ), 125.18 ( Fmoc $_{A R} \mathrm{C}=\mathrm{C}$ ), $124.74\left(\mathrm{Pbf}{ }_{A R} \mathrm{C}=\mathrm{C}\right), 120.17\left(\mathrm{Fmoc}_{\mathrm{AR}} \mathrm{C}=\mathrm{C}\right.$ ), 120.14 (FmoC $\left.{ }_{A R} \mathrm{C}=\mathrm{C}\right), 117.62\left(\mathrm{Pbf}{ }_{A R} \mathrm{C}=\mathrm{C}\right), 86.50\left(\mathrm{Pbf}_{\mathrm{q}}\right), 82.85\left(t-\mathrm{C}_{4} \mathrm{H}_{9} \mathrm{C}_{\mathrm{q}}\right), 67.27$ (Fmoc $\left.\mathrm{CH}_{2}\right), 53.65$ (Fmoc CH), 47.26 ( $\left.\operatorname{Arg} \alpha \mathrm{CH}\right), 43.35\left(\mathrm{Pbf} \mathrm{CH}_{2}\right), 40.95$
(Arg $\left.\mathrm{CH}_{2}\right), 30.92\left(\operatorname{Arg} \mathrm{CH}_{2}\right), 28.71\left(\mathrm{Pbf} \mathrm{CH}_{3}\right), 28.12\left(t-\mathrm{C}_{4} \mathrm{H}_{9} \mathrm{CH}_{3}\right), 25.08$ $\left(\operatorname{Arg} \mathrm{CH}_{2}\right), 19.42(\mathrm{Pbf} \mathrm{CH}), 18.05\left(\mathrm{Pbf} \mathrm{CH}_{3}\right), 12.60(\mathrm{Pbf} \mathrm{CH})$; (EtOAC and traces DCC).

LCMS (ESI): $m / z=706.8(100 \%)[\mathrm{M}+\mathrm{H}]^{+} ; t_{\mathrm{R}}=1.75 \mathrm{~min}$.

HRMS (ESI): $m / z[M+H]^{+}$calcd for $\mathrm{C}_{38} \mathrm{H}_{49} \mathrm{~N}_{4} \mathrm{O}_{7} \mathrm{~S}$ : 705.3316; found: 705.315 .

\section{tert-Butyl $N^{\omega}$-[(2,2,4,6,7-Pentamethyl-2,3-dihydrobenzofuran-5-} yl)sulfonyl]argininate (3a)

In a $250 \mathrm{~mL}$ round-bottomed flask, compound $\mathbf{2 a}$ (3.05 g, $4.33 \mathrm{mmol})$ was dissolved in piperidine-DMF (50 mL 1:4) and stirred for $80 \mathrm{~min}$. The organic solvent was then evaporated in vacuo and the crude reaction mixture purified 2 times by $\mathrm{FC}\left(\mathrm{CH}_{2} \mathrm{Cl}_{2}-\mathrm{MeOH}, 9: 1\right)$. All collected fractions were analyzed by TLC, combined, and evaporated to give compound $3 a$ ( $2.08 \mathrm{~g}, 4.31 \mathrm{mmol}$, quant) as a yellowish oil; $R_{f}=0.27$ $\left(\mathrm{CH}_{2} \mathrm{Cl}_{2}-\mathrm{MeOH}, 9: 1\right)$.

$\left.{ }^{1} \mathrm{H} \mathrm{NMR} \mathrm{(400} \mathrm{MHz,} \mathrm{CDCl}_{3}\right): \delta=6.32(\mathrm{t}, J=4.9 \mathrm{~Hz}, 1 \mathrm{H}$, Gua NH), $6.15(\mathrm{~s}$, $2 \mathrm{H}$, Gua NH), 3.35 (dd, $J=8.3,4.8 \mathrm{~Hz}, 1 \mathrm{H}, \operatorname{Arg} \alpha \mathrm{CH}$ ), 3.19 (pent, $J=6.5$ $\left.\mathrm{Hz}, 2 \mathrm{H}, \operatorname{Arg} \mathrm{CH}_{2}\right), 2.95\left(\mathrm{~s}, 2 \mathrm{H}, \mathrm{Pbf} \mathrm{CH}_{2}\right), 2.58\left(\mathrm{~s}, 3 \mathrm{H}, \mathrm{Pbf} \mathrm{CH}_{3}\right), 2.52(\mathrm{~s}, 3$ $\mathrm{H}, \mathrm{Pbf} \mathrm{CH}$ ), 2.09 (s, $3 \mathrm{H}, \mathrm{Pbf} \mathrm{CH}$ ), 1.83-1.68 (m, $\left.2 \mathrm{H}, \operatorname{Arg} \mathrm{CH}_{2}\right), 1.70(\mathrm{~s}$, $\left.2 \mathrm{H}, \mathrm{NH}_{2}\right), 1.68-1.49\left(\mathrm{~m}, 2 \mathrm{H}, \operatorname{Arg} \mathrm{CH}_{2}\right), 1.45\left(\mathrm{~s}, 6 \mathrm{H}, \mathrm{Pbf} 2 \times \mathrm{CH}_{3}\right), 1.45$ (s, $9 \mathrm{H}, t-\mathrm{C}_{4} \mathrm{H}_{9}$ ).

${ }^{13} \mathrm{C}$ NMR (101 MHz, $\mathrm{CDCl}_{3}$ ): $\delta=174.88$ ( $\mathrm{C}=\mathrm{O} t$-Bu ester), 158.83 ( $\mathrm{Pbf}$ ${ }_{A R} \mathrm{C}-\mathrm{O}$ ), 156.23 (Gua $\left.\mathrm{C}=\mathrm{N}\right), 138.53\left(\mathrm{Pbf}{ }_{\mathrm{AR}} \mathrm{C}=\mathrm{C}\right), 133.22\left(\mathrm{Pbf}{ }_{\mathrm{AR}} \mathrm{C}=\mathrm{C}\right)$, 132.49 $\left(\mathrm{Pbf}_{\mathrm{AR}} \mathrm{C}=\mathrm{C}\right), 124.70\left(\mathrm{Pbf}_{\mathrm{AR}} \mathrm{C}=\mathrm{C}\right), 117.58\left(\mathrm{Pbf}{ }_{\mathrm{AR}} \mathrm{C}=\mathrm{C}\right), 86.46(\mathrm{Pbf}$ $\left.\mathrm{C}_{\mathrm{q}}\right), 81.75\left(t-\mathrm{C}_{4} \mathrm{H}_{9} \mathrm{C}_{\mathrm{q}}\right), 54.52(\mathrm{Arg} \alpha \mathrm{CH}), 43.41\left(\mathrm{Pbf} \mathrm{CH}_{2}\right), 41.09(\mathrm{Arg}$ $\left.\mathrm{CH}_{2}\right), 31.04\left(\mathrm{Arg} \mathrm{CH} \mathrm{CH}_{2}\right), 28.75\left(\mathrm{Pbf} \mathrm{CH}_{3}\right), 28.19\left(t-\mathrm{C}_{4} \mathrm{H}_{9} \mathrm{CH}_{3}\right), 25.85(\mathrm{Arg}$ $\left.\left.\mathrm{CH}_{2}\right), 19.39\left(\mathrm{Pbf} \mathrm{CH}_{3}\right), 18.00(\mathrm{Pbf} \mathrm{CH})_{3}\right), 12.61\left(\mathrm{Pbf} \mathrm{CH}_{3}\right)$.

LCMS (ESI): $m / z=966.0(100 \%)\left[2 \times \mathrm{M}+\mathrm{H}^{+} ; t_{\mathrm{R}}=1.02 \mathrm{~min}\right.$.

HRMS (ESI): $m / z[M+H]^{+}$calcd for $\mathrm{C}_{23} \mathrm{H}_{39} \mathrm{~N}_{4} \mathrm{O}_{5} \mathrm{~S}$ : 483.2636; found: 483.2841.

tert-Butyl $N^{2}$-[3-(\{[(9H-Fluoren-9-yl)methoxy]carbonyl $\left.\} a m i n o\right)-4-$ (allyloxy)-4-oxobutanoyl]- $N^{\omega}$-[(2,2,4,6,7-pentamethyl-2,3-dihydrobenzofuran-5-yl)sulfonyl]argininate (4a)

In a $100 \mathrm{~mL}$ round-bottomed flask, compound $\mathbf{3 a}(1.58 \mathrm{~g}, 3.28 \mathrm{mmol})$ was dissolved in DMF $(20 \mathrm{~mL})$ and stirred. In another $50 \mathrm{~mL}$ pearshaped flask, Fmoc-Asp-OAll (1.31 g, $3.30 \mathrm{mmol}, 1.01$ equiv) and HATU (1.26 g, $3.30 \mathrm{mmol}, 1.01$ equiv) were dissolved in DMF (1 mL). Then, DIPEA ( $1.17 \mathrm{~mL}, 6.88 \mathrm{mmol}, 2.10$ equiv) was added and the mixture shaken for $4 \mathrm{~min}$. Afterwards, the contents of the pearshaped flask were transferred to the round-bottomed flask and stirred for $2 \mathrm{~h}$. DMF was partially evaporated in vacuo and the remaining organic phase was poured into $1 \mathrm{M}$ aq $\mathrm{HCl}(20 \mathrm{~mL})$ and extracted with $\mathrm{CH}_{2} \mathrm{Cl}_{2}(3 \times 40 \mathrm{~mL})$. The organic layers were combined and dried $\left(\mathrm{MgSO}_{4}\right)$ before being evaporated in vacuo. The crude reaction mixture was purified by $\mathrm{FC}$ (EtOAc- $\mathrm{CH}_{2} \mathrm{Cl}_{2}-\mathrm{MeOH}, 45: 45: 10$ ). All collected fractions were analyzed by TLC, combined, and evaporated to give compound $4 \mathbf{a}$ in $98 \%$ yield $(2.76 \mathrm{~g}, 3.21 \mathrm{mmol})$ as a colorless powder; $R_{f}=0.22\left(\right.$ EtOAc- $\left.\mathrm{CH}_{2} \mathrm{Cl}_{2}-\mathrm{MeOH}, 45: 45: 10\right)$.

${ }^{1} \mathrm{H}$ NMR (400 MHz, $\mathrm{CDCl}_{3}$ ): $\delta=10.06$ (s, $\left.1 \mathrm{H}, \mathrm{Gua} \mathrm{NH}\right), 8.73$ (s, $2 \mathrm{H}$, Gua $\mathrm{NH}), 7.76\left(\mathrm{~d}, J=7.6 \mathrm{~Hz}, 2 \mathrm{H}, \mathrm{Fmoc} \mathrm{CH}_{\mathrm{AR}}\right), 7.60$ (d, $J=7.5 \mathrm{~Hz}, 2 \mathrm{H}, \mathrm{Fmoc}$ $\left.\mathrm{CH}_{\mathrm{AR}}\right), 7.39\left(\mathrm{t}, J=7.4 \mathrm{~Hz}, 2 \mathrm{H}, \mathrm{Fmoc} \mathrm{CH}_{\mathrm{AR}}\right), 7.30(\mathrm{t}, J=7.5 \mathrm{~Hz}, 2 \mathrm{H}, \mathrm{Fmoc}$ $\left.\mathrm{CH}_{\mathrm{AR}}\right), 6.70(\mathrm{~d}, J=7.6 \mathrm{~Hz}, 1 \mathrm{H}$, amide $\mathrm{NH}), 5.99(\mathrm{~s}, 1 \mathrm{H}$, amide $\mathrm{NH}), 5.84$ (td, $J=10.7,5.2 \mathrm{~Hz}, 1 \mathrm{H}$, allyl C=CH), $5.28(\mathrm{~d}, J=17.1 \mathrm{~Hz}, 1 \mathrm{H}$, allyl $\left.\mathrm{C}=\mathrm{CH}_{2}\right), 5.22\left(\mathrm{dd}, J=10.4,1.3 \mathrm{~Hz}, 1 \mathrm{H}\right.$, allyl $\left.\mathrm{C}=\mathrm{CH}_{2}\right), 4.76-4.65(\mathrm{~m}, 1 \mathrm{H}$, $\alpha \mathrm{CH}$ ), 4.60 (s, $2 \mathrm{H}$, allyl $\mathrm{CH}_{2}$ ), 4.49-4.29 (m ovlp, $3 \mathrm{H}$, Fmoc $\mathrm{CH}_{2}+\alpha$ $\mathrm{CH}), 4.22(\mathrm{t}, J=6.9 \mathrm{~Hz}, 1 \mathrm{H}, \mathrm{Fmoc} \mathrm{CH}), 3.33(\mathrm{~d}, J=145.1 \mathrm{~Hz}, 2 \mathrm{H}, \mathrm{Arg}$ $\mathrm{CH}_{2}$ ), 2.96 (s, $2 \mathrm{H}, \mathrm{Pbf} \mathrm{CH}_{2}$ ), 2.95 (ddd, $J=56.7,16.3,4.6 \mathrm{~Hz}, 2 \mathrm{H}$, Asp 
$\mathrm{CH}_{2}$ ), 2.54 (s, $3 \mathrm{H}, \mathrm{Pbf} \mathrm{CH}_{3}$ ), 2.50 (s, $\left.3 \mathrm{H}, \mathrm{Pbf} \mathrm{CH}_{3}\right), 2.09$ (s, $3 \mathrm{H}, \mathrm{Pbf} \mathrm{CH}_{3}$ ),

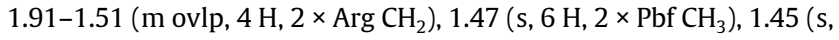
$\left.9 \mathrm{H}, t-\mathrm{C}_{4} \mathrm{H}_{9}\right)$.

${ }^{13} \mathrm{C}$ NMR (101 MHz, $\mathrm{CDCl}_{3}$ ): $\delta=171.47$ ( $\mathrm{C}=0$ amide), 171.01 ( $\mathrm{C}=0$ allyl ester), 170.77 ( $\mathrm{C}=\mathrm{O} t$-Bu ester), 161.14 $\left(\mathrm{Pbf}_{\mathrm{AR}} \mathrm{C}-\mathrm{O}\right), 156.31$ (Gua $\mathrm{C}=\mathrm{N}$ ), 153.81 (Fmoc $\mathrm{C}=\mathrm{O}$ ), 143.93 ( $\mathrm{Fmoc}{ }_{A R} \mathrm{C}=\mathrm{C}$ ), 143.85 (Fmoc ${ }_{A R} \mathrm{C}=\mathrm{C}$ ), $141.41\left(\mathrm{Fmoc}_{\mathrm{AR}} \mathrm{C}=\mathrm{C}\right), 140.95\left(\mathrm{Pbf}{ }_{\mathrm{AR}} \mathrm{C}=\mathrm{C}\right), 134.98\left(\mathrm{Pbf}{ }_{\mathrm{AR}} \mathrm{C}=\mathrm{C}\right), 131.38$ (allyl C=C), 127.88 (Fmoc $\left.{ }_{A R} \mathrm{C}=\mathrm{C}\right), 127.23\left(\mathrm{Fmoc}{ }_{A R} \mathrm{C}=\mathrm{C}\right), 125.85$ (Pbf $\left.{ }_{A R} C=C\right), 125.29\left(\right.$ Fmoc $\left._{A R} C=C\right), 120.12\left(\right.$ Fmoc $\left._{A R} \mathrm{C}=C\right), 119.11$ (allyl $\left.C=C\right)$, 118.74 $\left(\mathrm{Pbf}_{\mathrm{AR}} \mathrm{C}=\mathrm{C}\right), 87.58\left(\mathrm{Pbf} \mathrm{C}_{\mathrm{q}}\right), 83.53\left(t-\mathrm{C}_{4} \mathrm{H}_{9} \mathrm{C}_{\mathrm{q}}\right), 67.51\left(\mathrm{Fmoc} \mathrm{CH} \mathrm{CH}_{2}\right)$, 66.56 (allyl $\mathrm{CH}_{2}$ ), $51.66(\alpha \mathrm{CH}), 50.80(\alpha \mathrm{CH}), 47.22(\mathrm{Fmoc} \mathrm{CH}), 43.06$ $\left(\mathrm{Pbf} \mathrm{CH}_{2}\right), 40.90(\mathrm{Asp} \mathrm{CH}), 37.89\left(\mathrm{Arg} \mathrm{CH}_{2}\right), 30.93(\mathrm{Arg} \mathrm{CH}), 28.68(\mathrm{Pbf}$ $\left.\left.\mathrm{CH}_{3}\right), 28.05\left(t-\mathrm{C}_{4} \mathrm{H}_{9} \mathrm{CH}_{3}\right), 24.24\left(\mathrm{Arg} \mathrm{CH}_{2}\right), 19.38(\mathrm{Pbf} \mathrm{CH})_{3}\right), 17.75(\mathrm{Pbf}$ $\left.\mathrm{CH}_{3}\right), 12.59\left(\mathrm{Pbf} \mathrm{CH}_{3}\right)$.

LCMS (ESI): $m / z=862.3(100 \%)[\mathrm{M}+\mathrm{H}]^{+} ; t_{\mathrm{R}}=1.73 \mathrm{~min}$.

HRMS (ESI): $m / z[M+\mathrm{H}]^{+}$calcd for $\mathrm{C}_{45} \mathrm{H}_{58} \mathrm{~N}_{5} \mathrm{O}_{10} \mathrm{~S}: 860.3899$; found: 860.3888 .

\section{$N^{2}-\{[(9 H-F l u o r e n-9-y l) m e t h o x y]$ carbonyl $\}-N^{4}$-(1-(tert-butoxy)-1- oxo-5-\{3-[(2,2,4,6,7-pentamethyl-2,3-dihydrobenzofuran-5- yl)sulfonyl]guanidino\}pentan-2-yl)asparagine (5)}

In a $100 \mathrm{~mL}$ round-bottomed flask under $\mathrm{N}_{2}$, compound $\mathbf{4 a}$ (2.65 g, $3.08 \mathrm{mmol})$ was dissolved in $\mathrm{CH}_{2} \mathrm{Cl}_{2}(25 \mathrm{~mL})$. Then, $\mathrm{PhSiH}_{3}(750 \mu \mathrm{L}$, $6.16 \mathrm{mmol}, 2$ equiv) and $\mathrm{Pd}\left(\mathrm{PPh}_{3}\right)_{4}(361.8 \mathrm{mg}, 313.1 \mu \mathrm{mol}, 0.1$ equiv $)$ were added. The resulting solution was stirred for $2.5 \mathrm{~h}$, poured in 1 $\mathrm{M}$ aq $\mathrm{HCl}(20 \mathrm{~mL})$ and extracted with $\mathrm{CH}_{2} \mathrm{Cl}_{2}(3 \times 40 \mathrm{~mL})$. The organic layers were combined, dried $\left(\mathrm{MgSO}_{4}\right)$, and evaporated in vacuo. The crude reaction mixture was resuspended in $\mathrm{H}_{2} \mathrm{O}-\mathrm{MeCN}+0.1 \%$ TFA ( $50 \mathrm{~mL}, 1: 1)$ and lyophilized prior to purification. The product was then purified by $\mathrm{FC}\left(\mathrm{MeOH}-\mathrm{CH}_{2} \mathrm{Cl}_{2}, 1: 9,0\right.$ to $\left.1 \% \mathrm{AcOH}\right)$. The fractions containing the product were analyzed by TLC, collected, and evaporated in vacuo. Finally, compound $\mathbf{5}$ was obtained by semi-preparatrive HPLC using 4 runs of gradient 1 in $82 \%$ yield $(2.06 \mathrm{~g}, 2.52$ $\mathrm{mmol})$ as a colorless powder; $\mathrm{mp} 129^{\circ} \mathrm{C} ; R_{\mathrm{f}}=0.1\left(\mathrm{MeOH}-\mathrm{CH}_{2} \mathrm{Cl}_{2}, 1: 9\right)$. IR (neat): 3332 (w), 2975 (w), 2934 (w), 1723 (m), 1666 (m), 1547 (m), 1451 (m), 1370 (m), 1248 (m), 1201 (s), 1144 (s), 1091 (s), 992 (w), $845(\mathrm{~m}), 782(\mathrm{~m}), 760(\mathrm{~m}), 741(\mathrm{~s}), 722(\mathrm{~m}), 661(\mathrm{~m}), 641(\mathrm{~s}), 614$ (m) $\mathrm{cm}^{-1}$.

${ }^{1} \mathrm{H}$ NMR $\left(400 \mathrm{MHz}\right.$, DMSO- $\left.d_{6}\right): \delta=12.78\left(\mathrm{~s}, 1 \mathrm{H}, \mathrm{CO}_{2} \mathrm{H}\right), 8.17(\mathrm{~d}, J=7.4$ $\mathrm{Hz}, 1 \mathrm{H}, \mathrm{NH}$ amide), 7.88 (dd, $J=7.6,1.0 \mathrm{~Hz}, 2 \mathrm{H}, \mathrm{Fmoc} \mathrm{CH}_{\mathrm{AR}}$ ), 7.69 (d, $J=7.5 \mathrm{~Hz}, 2 \mathrm{H}$, Fmoc $\mathrm{CH}_{\mathrm{AR}}$ ), 7.45 (d, $J=8.4 \mathrm{~Hz}, 1 \mathrm{H}, \mathrm{NH}$ amide), 7.41 (t, $J=7.4 \mathrm{~Hz}, 2 \mathrm{H}$, Fmoc $\mathrm{CH}_{\mathrm{AR}}$ ), 7.32 (ddd, $J=7.5,2.0,1.2 \mathrm{~Hz}, 2 \mathrm{H}$, Fmoc $\left.\mathrm{CH}_{\mathrm{AR}}\right), 6.68(\mathrm{~s}, 1 \mathrm{H}$, Gua NH), $6.41(\mathrm{~s}, 1 \mathrm{H}, \mathrm{Gua} \mathrm{NH}), 4.35$ (td, $J=8.1,5.2$ $\mathrm{Hz}, 1 \mathrm{H}$, Fmoc CH), 4.29-4.16 (m ovlp, $3 \mathrm{H}$, Fmoc $\mathrm{CH}_{2}+\alpha \mathrm{CH}$ ), 4.06 (dt, $J=7.6,3.9 \mathrm{~Hz}, 1 \mathrm{H}, \alpha \mathrm{CH}), 3.11-2.97\left(\mathrm{~m}, 2 \mathrm{H}, \mathrm{Arg} \mathrm{CH}_{2}\right), 2.94(\mathrm{~s}, 2 \mathrm{H}, \mathrm{Pbf}$ $\left.\mathrm{CH}_{2}\right), 2.66-2.53\left(\mathrm{~m}, 2 \mathrm{H}\right.$, Asp $\left.\mathrm{CH}_{2}\right), 2.47\left(\mathrm{~s}, 3 \mathrm{H}, \mathrm{Pbf} \mathrm{CH}_{3}\right), 2.41(\mathrm{~s}, 3 \mathrm{H}$, Pbf $\mathrm{CH}_{3}$ ), 1.99 (s, $3 \mathrm{H}, \mathrm{Pbf} \mathrm{CH}$ ), 1.69-1.46 (m, $2 \mathrm{H}, \operatorname{Arg} \mathrm{CH}_{2}$ ), 1.45-1.31 (m ovlp, $\left.2 \mathrm{H}, \mathrm{Arg} \mathrm{CH}_{2}\right), 1.39\left(\mathrm{~s}, 6 \mathrm{H}, 2 \times \mathrm{Pbf} \mathrm{CH}_{3}\right), 1.37\left(\mathrm{~s}, 9 \mathrm{H}, t-\mathrm{C}_{4} \mathrm{H}_{9}\right)$.

${ }^{13} \mathrm{C}$ NMR (101 MHz, DMSO- $\left.d_{6}\right): \delta=173.01$ ( $\mathrm{C}=\mathrm{O}$ amide), 171.04 ( $\mathrm{C}=\mathrm{O}$ acid), 169.16 ( $\mathrm{C}=\mathrm{O} t$-Bu ester), $157.43\left(\mathrm{Pbf}_{\mathrm{AR}} \mathrm{C}-\mathrm{O}\right), 156.02$ (Fmoc $\left.\mathrm{C}=\mathrm{O}\right)$, 155.75 (Gua N=H), $143.78\left(\right.$ Fmoc $\left._{A R} \mathrm{C}=\mathrm{C}\right), 143.74\left(\mathrm{Fmoc}_{\mathrm{AR}} \mathrm{C}=\mathrm{C}\right), 140.69$ (Fmoc $\left.{ }_{A R} C=C\right), 140.67\left(\mathrm{Fmoc}_{A R} \mathrm{C}=\mathrm{C}\right), 137.22\left(\mathrm{Pbf}{ }_{A R} \mathrm{C}=\mathrm{C}\right), 131.41(\mathrm{Pbf}$ $\left.{ }_{A R} C=C\right), 127.62\left(\right.$ Fmoc $\left.{ }_{A R} C=C\right), 127.06\left(\right.$ Fmoc ${ }_{A R} C=C$ ), 125.22 (FmoC $\left.{ }_{A R} \mathrm{C}=\mathrm{C}\right), 124.30\left(\mathrm{Pbf}{ }_{A R} \mathrm{C}=\mathrm{C}\right), 120.10\left(\mathrm{FmoC}{ }_{A R} \mathrm{C}=\mathrm{C}\right), 116.23\left(\mathrm{Pbf}_{\mathrm{AR}} \mathrm{C}=\mathrm{C}\right)$, $99.50\left(\mathrm{Pbf}_{\mathrm{AR}} \mathrm{C}=\mathrm{C}\right), 86.28\left(\mathrm{Pbf} \mathrm{C}_{\mathrm{q}}\right), 80.55\left(t-\mathrm{C}_{4} \mathrm{H}_{9} \mathrm{C}_{\mathrm{q}}\right), 65.70\left(\mathrm{Fmoc} \mathrm{CH}_{2}\right)$, $52.57(\alpha \mathrm{CH}), 50.48$ (Fmoc CH), $46.57(\alpha \mathrm{CH}), 42.45\left(\mathrm{Pbf} \mathrm{CH}_{2}\right), 39.78$ (Arg $\mathrm{CH}_{2}$ ovlp with DMSO signal), 36.57(Asp $\left.\mathrm{CH}_{2}\right), 28.44\left(\operatorname{Arg} \mathrm{CH}_{2}\right)$, 28.28 ( $\left.\mathrm{Pbf} \mathrm{CH} \mathrm{CH}_{3}\right), 27.59\left(t-\mathrm{C}_{4} \mathrm{H}_{9} \mathrm{CH}_{3}\right), 25.37\left(\mathrm{Arg} \mathrm{CH}_{2}\right), 18.94\left(\mathrm{Pbf} \mathrm{CH}_{3}\right)$, $17.58\left(\mathrm{Pbf} \mathrm{CH}_{3}\right), 12.26\left(\mathrm{Pbf} \mathrm{CH}_{3}\right)$.
LCMS (ESI): $m / z=822.2(100 \%)[\mathrm{M}+\mathrm{H}]^{+} ; t_{\mathrm{R}}=1.59 \mathrm{~min}$. HRMS (ESI): $m / z[M+H]^{+}$calcd for $\mathrm{C}_{42} \mathrm{H}_{54} \mathrm{~N}_{5} \mathrm{O}_{10} \mathrm{~S}: 820.3586$; found: 820.3577.

\section{Preparation of Building Block 6}

\section{Methyl $N^{2}-\{[(9 H-F l u o r e n-9-y l)$ methoxy $]$ carbonyl $\}-N^{\omega}$ - $[(2,2,4,6,7-$} pentamethyl-2,3-dihydrobenzofuran-5-yl)sulfonyl]argininate (2b)

In a $50 \mathrm{~mL}$ round-bottomed flask, Fmoc-Arg(Pbf)-OH (1.65 g, 2.54 $\mathrm{mmol})$ was dissolved in neat $\mathrm{SOCl}_{2}(2 \mathrm{~mL})$ and stirred for $30 \mathrm{~min}$. Then the flask was placed on an ice bath and $\mathrm{MeOH}(10 \mathrm{~mL})$ was added dropwise under vigorous stirring. The mixture was stirred overnight at r.t. Then, it was poured into $1 \mathrm{M} \mathrm{aq} \mathrm{HCl}(20 \mathrm{~mL})$ and extracted with $\mathrm{CH}_{2} \mathrm{Cl}_{2}(3 \times 40 \mathrm{~mL})$. The organic layers were combined and dried $\left(\mathrm{MgSO}_{4}\right)$ before being evaporated in vacuo. The crude reaction mixture was purified by FC (EtOAc- $\mathrm{CH}_{2} \mathrm{Cl}_{2}, 1: 1$ ). All collected fractions were analyzed by TLC, combined, and evaporated to give compound 2b in $86 \%$ yield ( $1.45 \mathrm{~g}, 2.54 \mathrm{mmol}$ ) as a colorless powder; $R_{f}=0.26$ (EtOAc- $\mathrm{CH}_{2} \mathrm{Cl}_{2}, 1: 1$ ).

${ }^{1} \mathrm{H}$ NMR (400 MHz, $\mathrm{CDCl}_{3}$ ): $\delta=7.73\left(\mathrm{~d}, J=7.6 \mathrm{~Hz}, 2 \mathrm{H}, \mathrm{Fmoc} \mathrm{CH}_{\mathrm{AR}}\right.$ ), $7.55\left(\mathrm{~d}, J=7.1 \mathrm{~Hz}, 2 \mathrm{H}, \mathrm{Fmoc} \mathrm{CH}_{\mathrm{AR}}\right), 7.37\left(\mathrm{t}, J=7.5 \mathrm{~Hz}, 2 \mathrm{H}, \mathrm{Fmoc} \mathrm{CH}_{\mathrm{AR}}\right)$, 7.31-7.22 (m, 2 H, Fmoc $\mathrm{CH}_{\mathrm{AR}}$ ), 6.29-5.92 (m, $3 \mathrm{H}$, Gua NH), 5.67 (d, $J=8.2 \mathrm{~Hz}, 1 \mathrm{H}$, amide $\mathrm{NH}), 4.36\left(\mathrm{~d}, J=6.5 \mathrm{~Hz}, 2 \mathrm{H}, \mathrm{Fmoc} \mathrm{CH}_{2}\right), 4.34-$ $4.24(\mathrm{~m}, 1 \mathrm{H}, \mathrm{Fmoc} \mathrm{CH}), 4.16(\mathrm{t}, J=6.9 \mathrm{~Hz}, 1 \mathrm{H}, \operatorname{Arg} \alpha \mathrm{CH}), 3.70(\mathrm{~s}, 3 \mathrm{H}$, $\mathrm{OCH}_{3}$ ), 3.20 (ddt, $\left.J=18.8,13.5,7.1 \mathrm{~Hz}, 2 \mathrm{H}, \operatorname{Arg} \mathrm{CH}_{2}\right), 2.90(\mathrm{~s}, 2 \mathrm{H}, \mathrm{Pbf}$ $\left.\mathrm{CH}_{2}\right), 2.57\left(\mathrm{~s}, 3 \mathrm{H}, \mathrm{Pbf} \mathrm{CH}_{3}\right), 2.50\left(\mathrm{~s}, 3 \mathrm{H}, \mathrm{Pbf} \mathrm{CH}_{3}\right), 2.07\left(\mathrm{~s}, 3 \mathrm{H}, \mathrm{Pbf} \mathrm{CH}_{3}\right)$, 1.92-1.63 (m, $\left.2 \mathrm{H}, \operatorname{Arg} \mathrm{CH}_{2}\right), 1.63-1.51\left(\mathrm{~m}, 2 \mathrm{H}, \operatorname{Arg} \mathrm{CH}_{2}\right), 1.42(\mathrm{~s}, 6 \mathrm{H}$, $\left.2 \times \mathrm{Pbf} \mathrm{CH}_{3}\right)$.

${ }^{13} \mathrm{C}$ NMR (101 MHz, $\left.\mathrm{CDCl}_{3}\right): \delta=172.76$ ( $\mathrm{C}=\mathrm{O}$ Me ester), 158.91 ( $\mathrm{Pbf}$ $\left.{ }_{A R} C-O\right), 156.53$ (Fmoc $\left.C=0\right), 156.26$ (Gua $\left.C=N\right), 143.86$ (Fmoc $\left.{ }_{A R} C=C\right)$, 143.73 (Fmoc ${ }_{A R} \mathrm{C}=\mathrm{C}$ ), 141.41 ( $\left.\mathrm{Fmoc}{ }_{\mathrm{AR}} \mathrm{C}=\mathrm{C}\right), 141.39$ (Fmoc ${ }_{\mathrm{AR}} \mathrm{C}=\mathrm{C}$ ), $138.49\left(\mathrm{Pbf}{ }_{A R} \mathrm{C}=\mathrm{C}\right), 132.92\left(\mathrm{Pbf}{ }_{A R} \mathrm{C}=\mathrm{C}\right), 132.41\left(\mathrm{Pbf}{ }_{A R} \mathrm{C}=\mathrm{C}\right), 127.88$ $\left(\mathrm{Fmoc}_{\mathrm{AR}} \mathrm{C}=\mathrm{C}\right), 127.23\left(\mathrm{Fmoc}{ }_{\mathrm{AR}} \mathrm{C}=\mathrm{C}\right), 125.20\left(\mathrm{Fmoc}_{\mathrm{AR}} \mathrm{C}=\mathrm{C}\right), 124.77(\mathrm{Pbf}$ $\left.{ }_{A R} C=C\right), 120.13\left(\right.$ Fmoc $\left._{A R} C=C\right), 120.11\left(\mathrm{Fmoc}_{A R} \mathrm{C}=\mathrm{C}\right), 117.65\left(\mathrm{Pbf}_{\mathrm{AR}} \mathrm{C}=\mathrm{C}\right)$, 86.52 ( Pbf C $\left.\mathrm{q}_{\mathrm{q}}\right), 67.27\left(\mathrm{Fmoc} \mathrm{CH}_{2}\right), 53.49(\mathrm{Fmoc} \mathrm{CH}), 52.70\left(\mathrm{OCH}_{3}\right)$, $\left.47.23(\operatorname{Arg} \alpha \mathrm{CH}), 43.32(\mathrm{Pbf} \mathrm{CH})_{2}, 40.86(\operatorname{Arg~CH})_{2}\right), 30.29\left(\operatorname{Arg~} \mathrm{CH}_{2}\right)$, $28.70(\mathrm{Pbf} \mathrm{CH}), 25.29\left(\mathrm{Arg} \mathrm{CH}_{2}\right), 19.41\left(\mathrm{Pbf} \mathrm{CH} \mathrm{CH}_{3}\right), 18.06\left(\mathrm{Pbf} \mathrm{CH}_{3}\right)$, $12.59\left(\mathrm{Pbf} \mathrm{CH}_{3}\right)$; (EtOAc traces).

LCMS (ESI): $m / z=665.0(100 \%)\left[\mathrm{M}+\mathrm{H}^{+} ; t_{\mathrm{R}}=1.78 \mathrm{~min}\right.$.

HRMS (ESI): $m / z[M+H]^{+}$calcd for $\mathrm{C}_{35} \mathrm{H}_{43} \mathrm{~N}_{4} \mathrm{O}_{7} \mathrm{~S}$ : 663.2847; found: 663.2836 .

\section{Methyl $N^{\omega}$-[(2,2,4,6,7-Pentamethyl-2,3-dihydrobenzofuran-5- yl)sulfonyl]argininate (3b)}

In a $100 \mathrm{~mL}$ round-bottomed flask, compound $\mathbf{2 b}(1.41 \mathrm{~g}, 2.13 \mathrm{mmol})$ was dissolved in piperidine-DMF $(1: 4,10 \mathrm{~mL})$ and stirred for $1 \mathrm{~h}$. Then, $1 \mathrm{M}$ aq $\mathrm{HCl}(30 \mathrm{~mL})$ was added, and the mixture was extracted with $\mathrm{CH}_{2} \mathrm{Cl}_{2}(3 \times 30 \mathrm{~mL})$. The combined organic phases were removed and aq $\mathrm{NaHCO}_{3}$ was slowly added to the remaining aqueous phase until saturation (vigorous gas evolution). Subsequently, the aqueous phase was extracted with $\mathrm{CH}_{2} \mathrm{Cl}_{2}(3 \times 40 \mathrm{~mL})$. The organic layers were combined, dried $\left(\mathrm{MgSO}_{4}\right)$, and evaporated in vacuo. The crude reaction mixture was purified by $\mathrm{FC}\left(\mathrm{MeOH}-\mathrm{CH}_{2} \mathrm{Cl}_{2}, 1: 9\right)$. All the collected fractions were analyzed by TLC, combined, and evaporated to give compound $\mathbf{3 b}$ in $95 \%$ yield ( $885 \mathrm{mg}, 2.13 \mathrm{mmol}$ ) as a nearly transparent oil; $R_{f}=0.32\left(\mathrm{MeOH}-\mathrm{CH}_{2} \mathrm{Cl}_{2}, 1: 9\right)$. 
${ }^{1} \mathrm{H}$ NMR $\left(400 \mathrm{MHz}, \mathrm{CDCl}_{3}\right): \delta=6.39(\mathrm{~s}, 1 \mathrm{H}, \mathrm{Gua} \mathrm{NH}), 6.31(\mathrm{~s}, 2 \mathrm{H}$, Gua $\mathrm{NH}$ ), 3.70 (s, $3 \mathrm{H}, \mathrm{OCH}_{3}$ ), 3.48 (q, J = 4.0, $\left.2.5 \mathrm{~Hz}, 1 \mathrm{H}, \operatorname{Arg} \alpha \mathrm{CH}\right), 3.18$ (s, $\left.2 \mathrm{H}, \operatorname{Arg} \mathrm{CH}_{2}\right), 2.95(\mathrm{~s}, 2 \mathrm{H}, \mathrm{Pbf} \mathrm{CH})_{2}, 2.56\left(\mathrm{~s}, 3 \mathrm{H}, \mathrm{Pbf} \mathrm{CH}_{3}\right), 2.50(\mathrm{~s}, 3 \mathrm{H}$, $\left.\mathrm{Pbf} \mathrm{CH}_{3}\right), 2.10\left(\mathrm{~s}, 2 \mathrm{H}, \mathrm{NH}_{2}\right), 2.08\left(\mathrm{~s}, 3 \mathrm{H}, \mathrm{Pbf} \mathrm{CH}_{3}\right), 1.87-1.50(\mathrm{~m}, 4 \mathrm{H}, 2$ $\left.\times \operatorname{Arg} \mathrm{CH}_{2}\right), 1.45\left(\mathrm{~s}, 6 \mathrm{H}, 2 \times \mathrm{Pbf} \mathrm{CH}_{3}\right)$.

${ }^{13} \mathrm{C}$ NMR (101 MHz, $\mathrm{CDCl}_{3}$ ): $\delta=175.93$ ( $\mathrm{C}=\mathrm{O}$ Me ester), $158.85(\mathrm{Pbf}$ $\left.{ }_{A R} \mathrm{C}-\mathrm{O}\right), 156.40($ Gua $\mathrm{C}=\mathrm{N}), 138.43\left(\mathrm{Pbf}{ }_{\mathrm{AR}} \mathrm{C}=\mathrm{C}\right), 133.06\left(\mathrm{Pbf}{ }_{\mathrm{AR}} \mathrm{C}=\mathrm{C}\right)$, 132.36 $\left(\mathrm{Pbf}_{A R} \mathrm{C}=\mathrm{C}\right), 124.74\left(\mathrm{Pbf}_{\mathrm{AR}} \mathrm{C}=\mathrm{C}\right), 117.62\left(\mathrm{Pbf}_{\mathrm{AR}} \mathrm{C}=\mathrm{C}\right), 86.52(\mathrm{Pbf}$ $\left.\mathrm{C}_{\mathrm{q}}\right), 53.95(\mathrm{Arg} \alpha \mathrm{CH}), 52.32\left(\mathrm{OCH}_{3}\right), 43.38(\mathrm{Pbf} \mathrm{CH}), 40.90\left(\operatorname{Arg~} \mathrm{CH}_{2}\right)$, $\left.31.31\left(\mathrm{Arg} \mathrm{CH}_{2}\right), 28.74(\mathrm{Pbf} \mathrm{CH}), 25.75\left(\mathrm{Arg} \mathrm{CH}_{2}\right), 19.39(\mathrm{Pbf} \mathrm{CH})_{3}\right)$, $18.04\left(\mathrm{Pbf} \mathrm{CH}_{3}\right), 12.60\left(\mathrm{Pbf} \mathrm{CH}_{3}\right)$.

HRMS (ESI): $m / z[\mathrm{M}+\mathrm{H}]^{+}$calcd for $\mathrm{C}_{20} \mathrm{H}_{33} \mathrm{~N}_{4} \mathrm{O}_{5} \mathrm{~S}: 441.2166$; found: 441.2163 .

\section{Methyl $N^{2}$-[3-(\{[(9H-Fluoren-9-yl)methoxy]carbonyl $\left.\} a m i n o\right)-4-$ (allyloxy)-4-oxobutanoyl]- $N^{\omega}-[(2,2,4,6,7-p e n t a m e t h y l-2,3-d i h y-$ drobenzofuran-5-yl)sulfonyl]argininate (4b)}

In a $100 \mathrm{~mL}$ round-bottomed flask, compound $\mathbf{3 b}(845 \mathrm{mg}, 1.92$ $\mathrm{mmol})$ was dissolved in DMF $(10 \mathrm{~mL})$. In another small pear-shaped flask, Fmoc-Asp-OAll (796.3 mg, $2.01 \mathrm{mmol}, 1.05$ equiv) was dissolved in $0.4 \mathrm{M}$ HATU in DMF ( $5 \mathrm{~mL}, 2.01 \mathrm{mmol}$, 1.05 equiv). Then DIPEA ( $684 \mu \mathrm{L}, 4.03 \mathrm{mmol}, 2.1$ equiv) was added and the flask shaken for $2 \mathrm{~min}$. The contents of the pear-shaped flask were transferred to the $100 \mathrm{~mL}$ flask and the mixture was stirred overnight. Finally, the mixture was poured into $1 \mathrm{M}$ aq $\mathrm{HCl}(20 \mathrm{~mL})$ and extracted with $\mathrm{CH}_{2}$ $\mathrm{Cl}_{2}(3 \times 40 \mathrm{~mL})$. The organic layers were combined, $\operatorname{dried}\left(\mathrm{MgSO}_{4}\right)$, and evaporated in vacuo. The remaining DMF was removed using high vacuum $\left(10^{-2} \mathrm{mbar}\right)$. The crude reaction mixture was purified by FC (EtOAc- $\mathrm{CH}_{2} \mathrm{Cl}_{2}, 1: 1+1 \% \mathrm{MeOH}$ ). All collected fractions were analyzed by TLC, combined, and evaporated to give compound $\mathbf{4 b}$ in $87 \%$ yield $(1.37 \mathrm{~g}, 1.67 \mathrm{mmol})$ as a colorless powder; $R_{f}=0.26\left(\right.$ EtOAc- $\mathrm{CH}_{2} \mathrm{Cl}_{2}$, $1: 1+1 \% \mathrm{MeOH})$.

${ }^{1} \mathrm{H}$ NMR $\left(400 \mathrm{MHz}, \mathrm{CDCl}_{3}\right): \delta=7.75\left(\mathrm{~d}, J=7.5 \mathrm{~Hz}, 2 \mathrm{H}, \mathrm{Fmoc} \mathrm{CH}_{\mathrm{AR}}\right)$, 7.65-7.52 (m, $2 \mathrm{H}$, Fmoc $\left.\mathrm{CH}_{\mathrm{AR}}\right), 7.38\left(\mathrm{t}, J=7.4 \mathrm{~Hz}, 2 \mathrm{H}, \mathrm{Fmoc} \mathrm{CH}_{\mathrm{AR}}\right)$, 7.32-7.26 ( $\mathrm{m}, 2 \mathrm{H}$, Fmoc $\mathrm{CH}_{\mathrm{AR}}$ ), 6.98-6.85 ( $\mathrm{m}, 1 \mathrm{H}$, amide $\left.\mathrm{NH}\right), 6.17$ (d, $J=9.4 \mathrm{~Hz}, 1 \mathrm{H}$, amide $\mathrm{NH}), 6.16-6.01(\mathrm{~m}, 3 \mathrm{H}$, Gua NH), 5.84 (ddd, $J=$ 16.3, 10.8, $5.4 \mathrm{~Hz}, 1 \mathrm{H}$, allyl $\mathrm{C}=\mathrm{CH}), 5.28(\mathrm{~d}, J=17.1 \mathrm{~Hz}, 1 \mathrm{H}$, allyl $\left.\mathrm{C}=\mathrm{CH}_{2}\right), 5.19\left(\mathrm{dq}, J=10.5,1.3 \mathrm{~Hz}, 1 \mathrm{H}\right.$, allyl $\left.\mathrm{C}=\mathrm{CH}_{2}\right), 4.69-4.63(\mathrm{~m}, 1 \mathrm{H}$, $\alpha \mathrm{CH}), 4.61\left(\mathrm{~d}, J=5.5 \mathrm{~Hz}, 2 \mathrm{H}\right.$, allyl $\left.\mathrm{CH}_{2}\right), 4.57-4.47(\mathrm{~m}, 1 \mathrm{H}, \alpha \mathrm{CH})$, 4.45-4.17 (m ovlp, $3 \mathrm{H}$, Fmoc CH + Fmoc $\mathrm{CH}_{2}$ ), $3.70\left(\mathrm{~s}, 3 \mathrm{H}, \mathrm{OCH}_{3}\right), 3.20$ (s, $2 \mathrm{H}, \operatorname{Arg} \mathrm{CH}_{2}$ ), 2.93 (s, $2 \mathrm{H}, \mathrm{Pbf} \mathrm{CH}$ ), 3.04-2.74 (m, $2 \mathrm{H}, \mathrm{Asp} \mathrm{CH}_{2}$ ), 2.55 (s, $\left.3 \mathrm{H}, \mathrm{Pbf} \mathrm{CH}_{3}\right), 2.49$ (s, $\left.3 \mathrm{H}, \mathrm{Pbf} \mathrm{CH}_{3}\right), 2.07\left(\mathrm{~s}, 3 \mathrm{H}, \mathrm{Pbf} \mathrm{CH}_{3}\right), 1.78$ (ddt, $\left.J=57.5,13.5,5.8 \mathrm{~Hz}, 2 \mathrm{H}, \operatorname{Arg} \mathrm{CH}_{2}\right), 1.63-1.49\left(\mathrm{~m}, 2 \mathrm{H}, \operatorname{Arg} \mathrm{CH}_{2}\right.$ ), $1.44\left(\mathrm{~s}, 6 \mathrm{H}, 2 \times \mathrm{Pbf} \mathrm{CH}_{3}\right)$; (EtOAc traces).

${ }^{13} \mathrm{C}$ NMR (101 MHz, $\mathrm{CDCl}_{3}$ ): $\delta=172.52$ ( $\mathrm{C}=\mathrm{O}$ amide), 171.30 ( $\mathrm{C}=\mathrm{O}$ allyl), 170.65 ( $\mathrm{C}=\mathrm{O}$ Me ester), $158.97\left(\mathrm{Pbf}{ }_{\mathrm{AR}} \mathrm{C}-\mathrm{O}\right), 156.37$ (Gua $\left.\mathrm{C}=\mathrm{N}\right)$, 156.26 (Fmoc C=O), 143.99 (Fmoc $\left.{ }_{A R} \mathrm{C}=\mathrm{C}\right), 143.88$ (Fmoc $\left.{ }_{A R} \mathrm{C}=\mathrm{C}\right)$, $141.39\left(\mathrm{FmoC}_{\mathrm{AR}} \mathrm{C}=\mathrm{C}\right), 138.50\left(\mathrm{Pbf}_{\mathrm{AR}} \mathrm{C}=\mathrm{C}\right), 132.84\left(\mathrm{Pbf}{ }_{\mathrm{AR}} \mathrm{C}=\mathrm{C}\right), 132.41$ ( $\mathrm{Pbf}{ }_{\mathrm{AR}} \mathrm{C}=\mathrm{C}$ ), 131.57 (allyl C=C), 127.87 (Fmoc ${ }_{A R} \mathrm{C}=\mathrm{C}$ ), 127.23 (FmoC $\left.{ }_{A R} C=C\right), 125.39\left(\mathrm{FmoC}_{A R} \mathrm{C}=\mathrm{C}\right), 125.32\left(\mathrm{FmoC}_{A R} \mathrm{C}=\mathrm{C}\right), 124.84\left(\mathrm{Pbf}_{\mathrm{AR}} \mathrm{C}=\mathrm{C}\right)$, 120.11 ( Fmoc $\left._{A R} \mathrm{C}=\mathrm{C}\right), 118.78$ (allyl $\left.\mathrm{C}=\mathrm{C}\right), 117.72\left(\mathrm{Pbf}_{\mathrm{AR}} \mathrm{C}=\mathrm{C}\right), 86.59(\mathrm{Pbf}$ $\left.\mathrm{C}_{\mathrm{q}}\right), 67.46\left(\mathrm{Fmoc} \mathrm{CH}_{2}\right), 66.48$ (allyl $\left.\mathrm{CH}_{2}\right), 52.76\left(\mathrm{OCH}_{3}\right), 51.94(\alpha \mathrm{CH})$, $51.08(\alpha \mathrm{CH}), 47.20(\mathrm{Fmoc} \mathrm{CH}), 43.34\left(\mathrm{Pbf} \mathrm{CH}_{2}\right), 40.67\left(\mathrm{Arg} \mathrm{CH}_{2}\right), 37.68$

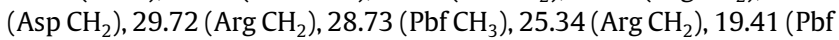
$\left.\mathrm{CH}_{3}\right), 18.06\left(\mathrm{Pbf} \mathrm{CH}_{3}\right), 12.61\left(\mathrm{Pbf} \mathrm{CH}_{3}\right)$; (EtOAc traces).

LCMS (ESI): $m / z=820.2(100 \%)[\mathrm{M}+\mathrm{H}]^{+} ; t_{\mathrm{R}}=1.64 \mathrm{~min}$.

HRMS (ESI): $m / z[\mathrm{M}+\mathrm{H}]^{+}$calcd for $\mathrm{C}_{42} \mathrm{H}_{52} \mathrm{~N}_{5} \mathrm{O}_{10} \mathrm{~S}$ : 818.3429; found: 818.3435.
$N^{2}-\{[(9 H-F l u o r e n-9-y l) m e t h o x y]$ carbonyl $\}-N^{4}-(1-$ methoxy-1-oxo5-\{3-[(2,2,4,6,7-pentamethyl-2,3-dihydrobenzofuran-5-yl)sulfonyl guanidino\}pentan-2-yl)asparagine (6)

In a $100 \mathrm{~mL}$ round-bottomed flask, compound $\mathbf{4 b}(1.19 \mathrm{~g}, 1.46 \mathrm{mmol})$ was dissolved in $\mathrm{CH}_{2} \mathrm{Cl}_{2}(10 \mathrm{~mL})$ and $\mathrm{N}_{2}$ was bubbled through the solution for $10 \mathrm{~min}$. Then, $\mathrm{PhSiH}_{3}$ (4 mL, $32.45 \mathrm{mmol}, 22.25$ equiv) and $\mathrm{Pd}\left(\mathrm{PPh}_{3}\right)_{4}$ were added (66.6 mg, $57.6 \mu \mathrm{mol}, 0.04$ equiv). The solution was stirred for $2 \mathrm{~h}$. Then, the mixture was poured into $1 \mathrm{M}$ aq $\mathrm{HCl}(20$ $\mathrm{mL})$ and extracted with $\mathrm{CH}_{2} \mathrm{Cl}_{2}(3 \times 40 \mathrm{~mL})$. The organic layers were combined and dried $\left(\mathrm{MgSO}_{4}\right)$ before being evaporated in vacuo. The crude reaction mixture was separated by $\mathrm{FC}\left(\mathrm{CH}_{2} \mathrm{Cl}_{2}-\mathrm{MeOH}, 95: 5+\right.$ $0.5 \%$ TFA). All the fractions containing the product (TLC test) were combined and evaporated. Compound $\mathbf{6}$ was isolated by semi-preparative HPLC with 3 injections using gradient 2 in $51 \%$ yield $(575 \mathrm{mg}$, $0.74 \mathrm{mmol})$ as a colorless powder; $\mathrm{mp} 118{ }^{\circ} \mathrm{C} ; R_{f}=0.29(\mathrm{MeOH}-$ $\left.\mathrm{CH}_{2} \mathrm{Cl}_{2}, 5: 95+0.5 \% \mathrm{TFA}\right)$.

IR (neat): 3332 (w), 2972 (w), 2936 (w), 1723 (m), 1663 (s), $1574(\mathrm{~m})$, $1544(\mathrm{~m}) 1450(\mathrm{~m}), 1372(\mathrm{w}), 1388(\mathrm{w}), 1331(\mathrm{~m}), 1289(\mathrm{~m}), 1239$ (m), 1200 (s), $1164(\mathrm{~s}), 1140(\mathrm{~s}), 1091(\mathrm{~s}), 992(\mathrm{~m}), 849(\mathrm{~m}), 781(\mathrm{~m})$, $760(\mathrm{~m}), 741(\mathrm{~s}), 722(\mathrm{~m}), 641(\mathrm{~s}), 613(\mathrm{~s}) \mathrm{cm}^{-1}$.

${ }^{1} \mathrm{H}$ NMR (400 MHz, DMSO- $d_{6}$ ): $\delta=8.31(\mathrm{~d}, J=7.4 \mathrm{~Hz}, 1 \mathrm{H}$, amide NH), $7.88\left(\mathrm{~d}, J=7.4 \mathrm{~Hz}, 2 \mathrm{H}, \mathrm{Fmoc} \mathrm{CH}_{\mathrm{AR}}\right), 7.69\left(\mathrm{~d}, J=7.5 \mathrm{~Hz}, 2 \mathrm{H}, \mathrm{Fmoc} \mathrm{CH}_{\mathrm{AR}}\right)$, $7.46(\mathrm{~d}, J=8.3 \mathrm{~Hz}, 1 \mathrm{H}$, amide $\mathrm{NH}), 7.41\left(\mathrm{t}, J=7.4 \mathrm{~Hz}, 2 \mathrm{H}, \mathrm{Fmoc}_{\mathrm{CH}} \mathrm{AR}_{\mathrm{AR}}\right.$, 7.36-7.28 (m, 2 H, Fmoc $\mathrm{CH}_{\mathrm{AR}}$ ), $6.69(\mathrm{~s}, 1 \mathrm{H}$, Gua NH), $6.41(\mathrm{~s}, 1 \mathrm{H}$, Gua $\mathrm{NH}), 4.34(\mathrm{td}, J=8.1,5.3 \mathrm{~Hz}, 1 \mathrm{H}, \mathrm{Fmoc} \mathrm{CH}$ ), 4.30-4.14 (m ovlp, $4 \mathrm{H}$ Fmoc $\left.\mathrm{CH}_{2}+2 \alpha \mathrm{CH}\right), 3.59\left(\mathrm{~s}, 3 \mathrm{H}, \mathrm{OCH}_{3}\right), 3.01(\mathrm{~d}, J=6.1 \mathrm{~Hz}, 2 \mathrm{H}, \mathrm{Arg}$ $\left.\mathrm{CH}_{2}\right), 2.94\left(\mathrm{~s}, 2 \mathrm{H}, \mathrm{Pbf} \mathrm{CH} \mathrm{CH}_{2}\right), 2.69-2.52\left(\mathrm{~m}, 2 \mathrm{H}, \mathrm{Asp} \mathrm{CH} \mathrm{CH}_{2}\right), 2.47(\mathrm{~s}, 3 \mathrm{H}$, Pbf $\mathrm{CH}_{3}$ ), 2.41 (s, $\left.3 \mathrm{H}, \mathrm{Pbf} \mathrm{CH}_{3}\right), 1.99$ (s, $\left.3 \mathrm{H}, \mathrm{Pbf} \mathrm{CH}_{3}\right), 1.73-1.47$ (m, 2 $\left.\mathrm{H}, \operatorname{Arg} \mathrm{CH}_{2}\right), 1.39(\mathrm{~s}, 6 \mathrm{H}, 2 \times \mathrm{Pbf} \mathrm{CH}), 1.47-1.28(\mathrm{~m}, 2 \mathrm{H} \mathrm{Arg} \mathrm{CH})$.

${ }^{13} \mathrm{C}$ NMR (101 MHz, DMSO- $\left.d_{6}\right): \delta=172.97$ ( $\mathrm{C}=\mathrm{O}$ amide), 172.35 ( $\mathrm{C}=\mathrm{O}$ Me ester), $169.31\left(\mathrm{CO}_{2} \mathrm{H}\right), 157.45$ ( $\left.\mathrm{Pbf}{ }_{\mathrm{AR}} \mathrm{C}-\mathrm{O}\right), 156.02$ (Fmoc $\mathrm{C}=\mathrm{O}$ ), 155.76 (Gua C=N), $143.79\left(\right.$ Fmoc $\left._{A R} \mathrm{C}=\mathrm{C}\right), 143.75$ ( $\left.\mathrm{Fmoc}_{\mathrm{AR}} \mathrm{C}=\mathrm{C}\right), 140.70$

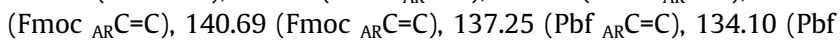
$\left.{ }_{A R} \mathrm{C}=\mathrm{C}\right), 131.43\left(\mathrm{Pbf}_{\mathrm{AR}} \mathrm{C}=\mathrm{C}\right), 127.63\left(\mathrm{Fmoc}_{\mathrm{AR}} \mathrm{C}=\mathrm{C}\right), 127.07\left(\mathrm{Fmoc}_{\mathrm{AR}} \mathrm{C}=\mathrm{C}\right)$, 125.23 (Fmoc $\left.{ }_{A R} \mathrm{C}=\mathrm{C}\right), 124.33\left(\mathrm{Pbf}_{\mathrm{AR}} \mathrm{C}=\mathrm{C}\right), 120.10\left(\mathrm{Fmoc}_{\mathrm{AR}} \mathrm{C}=\mathrm{C}\right), 116.26$ (Pbf $\left.{ }_{A R} \mathrm{C}=\mathrm{C}\right), 86.30\left(\mathrm{Pbf} \mathrm{C}_{\mathrm{q}}\right), 65.70\left(\mathrm{Fmoc} \mathrm{CH}_{2}\right), 51.80(\alpha \mathrm{CH}), 51.79$ $\left(\mathrm{OCH}_{3}\right), 50.49(\mathrm{Fmoc} \mathrm{CH}), 46.59(\alpha \mathrm{CH}), 42.44\left(\mathrm{Pbf} \mathrm{CH}_{2}\right), 39.73(\mathrm{Arg}$ $\mathrm{CH}_{2}$ ovlp with DMSO signal), $36.59\left(\mathrm{Asp} \mathrm{CH}_{2}\right), 28.28\left(\mathrm{Pbf} \mathrm{CH}_{3}\right), 28.20$ $(\operatorname{Arg~CH}), 25.40\left(\operatorname{Arg~CH} C_{2}\right), 18.94\left(\mathrm{Pbf} \mathrm{CH}_{3}\right), 17.58\left(\mathrm{Pbf} \mathrm{CH}_{3}\right), 12.26(\mathrm{Pbf}$ $\mathrm{CH}_{3}$ ).

LC (ESI): $m / z=778.9(100 \%)[\mathrm{M}+\mathrm{H}]^{+} ; t_{\mathrm{R}}=1.65 \mathrm{~min}$.

HRMS (ESI): $m / z[M+H]^{+}$calcd for $\mathrm{C}_{39} \mathrm{H}_{48} \mathrm{~N}_{5} \mathrm{O}_{10} \mathrm{~S}: 778.3116$; found: 778.3120 .

\section{Preparation of Building Block 7}

(9H-Fluoren-9-yl)methyl-(1-(dimethylamino)-1-oxo-5-\{3[(2,2,4,6,7-pentamethyl-2,3-dihydrobenzofuran-5-yl)sulfonyl]guanidino\}pentan-2-yl)carbamate (2c)

In a $50 \mathrm{~mL}$ round-bottomed flask, Fmoc- $\mathrm{Arg}(\mathrm{Pbf})-\mathrm{OH}(1.65 \mathrm{~g}, 2.54$ $\mathrm{mmol}$ ) was dissolved in neat $\mathrm{SOCl}_{2}(2 \mathrm{~mL})$. The solution was stirred for 30 min. Then, $\mathrm{SOCl}_{2}$ was evaporated using a gentle $\mathrm{N}_{2}$ flow. Afterwards, $2 \mathrm{M} \mathrm{HNMe}_{2}$ in THF (11.5 mL, $22.94 \mathrm{mmol}, 10$ equiv) was added dropwise by cooling the mixture on ice. The mixture was stirred overnight at r.t., poured into $1 \mathrm{M}$ aq $\mathrm{HCl}(20 \mathrm{~mL})$ and extracted with $\mathrm{CH}_{2} \mathrm{Cl}_{2}$ $(3 \times 40 \mathrm{~mL})$. The organic layers were combined and dried $\left(\mathrm{MgSO}_{4}\right)$ before being evaporated in vacuo. The crude reaction mixture was purified by $\mathrm{FC}\left(\mathrm{CH}_{2} \mathrm{Cl}_{2}-\mathrm{MeOH}\right.$, 95:5). All fractions collected were analyzed 
by TLC, combined, and evaporated to afford compound $\mathbf{2 c}$ in $68 \%$ yield $(1.05 \mathrm{~g}, 2.29 \mathrm{mmol})$ as a yellowish solid; $R_{f}=0.41\left(\mathrm{CH}_{2} \mathrm{Cl}_{2}-\mathrm{MeOH}\right.$, 95:5).

${ }^{1} \mathrm{H}$ NMR $\left(400 \mathrm{MHz}, \mathrm{CDCl}_{3}\right): \delta=7.74\left(\mathrm{~d}, J=7.5 \mathrm{~Hz}, 2 \mathrm{H}, \mathrm{Fmoc} \mathrm{CH}_{\mathrm{AR}}\right)$, 7.56 (dd, $J=7.3,3.5 \mathrm{~Hz}, 2 \mathrm{H}$, Fmoc $\mathrm{CH}_{\mathrm{AR}}$ ), 7.42-7.34 (m, $2 \mathrm{H}$, Fmoc $\left.\mathrm{CH}_{\mathrm{AR}}\right), 7.31-7.24\left(\mathrm{~m}, 2 \mathrm{H}, \mathrm{Fmoc} \mathrm{CH}_{\mathrm{AR}}\right), 6.21(\mathrm{~s}, 1 \mathrm{H}, \mathrm{Gua} \mathrm{NH}), 6.12(\mathrm{~s}, 2$ $\mathrm{H}$, Gua NH), $6.04(\mathrm{~d}, J=8.2 \mathrm{~Hz}, 1 \mathrm{H}$, amide $\mathrm{NH}), 4.72-4.56(\mathrm{~m}, 1 \mathrm{H}$, Fmoc CH), 4.44-4.26 (m, $\left.2 \mathrm{H}, \mathrm{Fmoc} \mathrm{CH}_{2}\right), 4.16(\mathrm{t}, J=6.9 \mathrm{~Hz}, 1 \mathrm{H}, \operatorname{Arg} \alpha$ $\mathrm{CH}), 3.40-3.08\left(\mathrm{~m}, 2 \mathrm{H}, \operatorname{Arg} \mathrm{CH}_{2}\right), 3.01\left(\mathrm{~s}, 3 \mathrm{H}, \mathrm{NCH}_{3}\right), 2.93(\mathrm{~s}, 3 \mathrm{H}$, $\left.\mathrm{NCH}_{3}\right), 2.92\left(\mathrm{~s}, 2 \mathrm{H}, \mathrm{Pbf} \mathrm{CH}_{2}\right), 2.58\left(\mathrm{~s}, 3 \mathrm{H}, \mathrm{Pbf} \mathrm{CH}_{3}\right), 2.51(\mathrm{~s}, 3 \mathrm{H}, \mathrm{Pbf}$ $\left.\mathrm{CH}_{3}\right), 2.08$ (s, $3 \mathrm{H}, \mathrm{Pbf} \mathrm{CH}$ ), 1.81-1.66 (m, $2 \mathrm{H}, \operatorname{Arg} \mathrm{CH}_{2}$ ), 1.61 (dd, $J=$ 13.8, 7.1 Hz, $\left.2 \mathrm{H}, \operatorname{Arg~} \mathrm{CH}_{2}\right), 1.43\left(\mathrm{~s}, 6 \mathrm{H}, 2 \times \mathrm{Pbf} \mathrm{CH}_{3}\right)$.

${ }^{13} \mathrm{C}$ NMR (101 MHz, $\mathrm{CDCl}_{3}$ ): $\delta=171.65$ ( $\mathrm{C}=\mathrm{O} \mathrm{NMe}_{2}$ amide), $158.83(\mathrm{Pbf}$ ${ }_{A r} \mathrm{C}-\mathrm{O}$ ), 156.79 (Gua C=N), 156.20 (Fmoc $\left.\mathrm{C}=\mathrm{O}\right), 143.87$ ( $\mathrm{FmoC}{ }_{\mathrm{AR}} \mathrm{C}=\mathrm{C}$ ), 143.74 (Fmoc ${ }_{A R} \mathrm{C}=\mathrm{C}$ ), 141.43 (Fmoc ${ }_{A R} \mathrm{C}=\mathrm{C}$ ), 141.39 (Fmoc ${ }_{\mathrm{AR}} \mathrm{C}=\mathrm{C}$ ), $138.49\left(\mathrm{Pbf}{ }_{A R} \mathrm{C}=\mathrm{C}\right), 133.14\left(\mathrm{Pbf}{ }_{\mathrm{AR}} \mathrm{C}=\mathrm{C}\right), 132.42\left(\mathrm{Pbf}{ }_{\mathrm{AR}} \mathrm{C}=\mathrm{C}\right), 127.91$ (Fmoc ${ }_{A R} \mathrm{C}=\mathrm{C}$ ), 127.87 (Fmoc $\left.{ }_{A R} \mathrm{C}=\mathrm{C}\right), 127.22\left(\mathrm{Fmoc}{ }_{\mathrm{AR}} \mathrm{C}=\mathrm{C}\right), 125.24$ ( Fmoc $_{A R} \mathrm{C}=\mathrm{C}$ ), 125.20 ( Fmoc $\left._{A R} \mathrm{C}=\mathrm{C}\right), 124.72\left(\mathrm{Pbf}_{\mathrm{AR}} \mathrm{C}=\mathrm{C}\right), 120.15$ (Fmoc $\left.{ }_{A R} \mathrm{C}=\mathrm{C}\right), 120.11\left(\mathrm{FmoC}_{\mathrm{AR}} \mathrm{C}=\mathrm{C}\right), 117.59\left(\mathrm{Pbf}_{\mathrm{AR}} \mathrm{C}=\mathrm{C}\right), 86.49\left(\mathrm{Pbf} \mathrm{C}_{\mathrm{q}}\right), 67.26$ $\left(\mathrm{Fmoc} \mathrm{CH}_{2}\right), 50.27$ (Fmoc CH), 47.26 (Arg $\left.\alpha \mathrm{CH}\right), 43.36\left(\mathrm{Pbf} \mathrm{CH}_{2}\right), 41.13$ $\left(\operatorname{Arg} \mathrm{CH}_{2}\right), 37.21\left(\mathrm{NCH}_{3}\right), 35.96\left(\mathrm{NCH}_{3}\right), 30.79\left(\operatorname{Arg} \mathrm{CH}_{2}\right), 28.72(\mathrm{Pbf}$ $\left.\mathrm{CH}_{3}\right), 24.71\left(\mathrm{Arg} \mathrm{CH}_{2}\right), 19.41\left(\mathrm{Pbf} \mathrm{CH}_{3}\right), 18.05\left(\mathrm{Pbf} \mathrm{CH}_{3}\right), 12.61(\mathrm{Pbf}$ $\left.\mathrm{CH}_{3}\right)$.

HRMS (ESI): $m / z[M+H]^{+}$calcd for $\mathrm{C}_{36} \mathrm{H}_{46} \mathrm{~N}_{5} \mathrm{O}_{6} \mathrm{~S}: 676.3163$; found: 676.3152 .

\section{2-Amino- $N, N$-dimethyl-5-\{3-[(2,2,4,6,7-pentamethyl-2,3-dihydro- benzofuran-5-yl)sulfonyl]guanidino\}pentanamide (3c)}

In a $100 \mathrm{~mL}$ round-bottomed flask, compound $2 \mathrm{c}(989 \mathrm{mg}, 1.46$ $\mathrm{mmol})$ was dissolved in piperidine-DMF $(1: 4,10 \mathrm{~mL})$. The solution was stirred for $1 \mathrm{~h}$. Then, $1 \mathrm{M}$ aq $\mathrm{HCl}(30 \mathrm{~mL})$ was added, and the mixture was extracted with $\mathrm{CH}_{2} \mathrm{Cl}_{2}(3 \times 30 \mathrm{~mL})$. The combined organic phases were removed and aq $\mathrm{NaHCO}_{3}$ was slowly added to the remaining aqueous phase until saturation (vigorous gas evolution). The aqueous phase was extracted with $\mathrm{CH}_{2} \mathrm{Cl}_{2}(3 \times 40 \mathrm{~mL})$. The organic layers were combined, dried $\left(\mathrm{MgSO}_{4}\right)$, and evaporated in vacuo. The crude reaction mixture was purified by $\mathrm{FC}\left(\mathrm{MeCN}-\mathrm{Et}_{3} \mathrm{~N}, 99: 1,0\right.$ to $10 \% \mathrm{MeOH})$. All collected fractions were analyzed by TLC, combined, and evaporated to give compound $3 \mathrm{c}$ in quantitative yield $(698 \mathrm{mg}$, $1.46 \mathrm{mmol})$ as a yellow oil; $R_{f}=0.11\left(\mathrm{MeOH}-\mathrm{MeCN}, 1: 9+1 \% \mathrm{Et}_{3} \mathrm{~N}\right)$.

${ }^{1} \mathrm{H} \mathrm{NMR}\left(400 \mathrm{MHz}, \mathrm{CDCl}_{3}\right): \delta=6.57(\mathrm{~s}, 1 \mathrm{H}, \mathrm{Gua} \mathrm{NH}), 6.38(\mathrm{~s}, 2 \mathrm{H}$, Gua $\mathrm{NH})$, 3.69-3.61 (m, $1 \mathrm{H}, \operatorname{Arg} \alpha \mathrm{CH}), 3.19\left(\mathrm{~s}, 2 \mathrm{H}, \operatorname{Arg} \mathrm{CH}_{2}\right), 3.01(\mathrm{~s}, 3 \mathrm{H}$, $\left.\mathrm{NCH}_{3}\right), 2.94\left(\mathrm{~s}, 3 \mathrm{H}, \mathrm{NCH}_{3}\right), 2.94\left(\mathrm{~s}, 2 \mathrm{H}, \mathrm{Pbf} \mathrm{CH}_{2}\right), 2.57$ (s, $3 \mathrm{H}, \mathrm{Pbf} \mathrm{CH}_{3}$ ), $2.50\left(\mathrm{~s}, 3 \mathrm{H}, \mathrm{Pbf} \mathrm{CH}_{3}\right), 2.23\left(\mathrm{~s}, 2 \mathrm{H}, \mathrm{NH}_{2}\right), 2.08\left(\mathrm{~s}, 3 \mathrm{H}, \mathrm{Pbf} \mathrm{CH}_{3}\right), 1.74-$ $1.60\left(\mathrm{~m}, 2 \mathrm{H}, \operatorname{Arg} \mathrm{CH}_{2}\right), 1.45\left(\mathrm{~s}, 6 \mathrm{H}, 2 \times \mathrm{Pbf} \mathrm{CH}_{3}\right), 1.25\left(\mathrm{~s}, 2 \mathrm{H}, \operatorname{Arg} \mathrm{CH}_{2}\right)$.

${ }^{13} \mathrm{C} \mathrm{NMR}\left(101 \mathrm{MHz}, \mathrm{CDCl}_{3}\right): \delta=174.93\left(\mathrm{C}=\mathrm{O} \mathrm{NMe}_{2}\right.$ amide $), 158.78(\mathrm{Pbf}$ $\left.{ }_{A R} \mathrm{C}-\mathrm{O}\right), 156.51$ (Gua $\mathrm{C}=\mathrm{N}$ ), 138.41 ( $\left.\mathrm{Pbf}{ }_{\mathrm{AR}} \mathrm{C}=\mathrm{C}\right), 133.26\left(\mathrm{Pbf}{ }_{\mathrm{AR}} \mathrm{C}=\mathrm{C}\right)$, 132.37 $\left(\mathrm{Pbf}_{A R} \mathrm{C}=\mathrm{C}\right), 124.70\left(\mathrm{Pbf}_{A R} \mathrm{C}=\mathrm{C}\right), 117.57\left(\mathrm{Pbf}_{\mathrm{AR}} \mathrm{C}=\mathrm{C}\right), 86.49(\mathrm{Pbf}$ $\left.\mathrm{C}_{\mathrm{q}}\right), 70.71(\mathrm{Arg} \alpha \mathrm{CH}), 43.40(\mathrm{Pbf} \mathrm{CH}), 40.99\left(\mathrm{Arg} \mathrm{CH}_{2}\right), 37.05\left(\mathrm{NCH}_{3}\right)$, 36.11 $\left(\mathrm{NCH}_{3}\right), 29.84\left(\operatorname{Arg} \mathrm{CH}_{2}\right), 28.75\left(\mathrm{Pbf} \mathrm{CH}_{3}\right), 25.74\left(\operatorname{Arg} \mathrm{CH}_{2}\right), 19.41$ ( $\left.\mathrm{Pbf} \mathrm{CH}_{3}\right), 18.06\left(\mathrm{Pbf} \mathrm{CH}_{3}\right), 12.62\left(\mathrm{Pbf} \mathrm{CH}_{3}\right)$.

LCMS (ESI): $m / z=453.9(100 \%)[\mathrm{M}+\mathrm{H}]^{+} ; t_{\mathrm{R}}=1.04 \mathrm{~min}$.

HRMS (ESI): $m / z[\mathrm{M}+\mathrm{H}]^{+}$calcd for $\mathrm{C}_{21} \mathrm{H}_{36} \mathrm{~N}_{5} \mathrm{O}_{4} \mathrm{~S}: 454.2483$; found: 454.2482 .
Allyl $N^{2}-\{[(9 H-F l u o r e n-9-y l) m e t h o x y]$ carbonyl $\}-N^{4}$-(1-(dimethylamino)-1-oxo-5-\{3-[(2,2,4,6,7-pentamethyl-2,3-dihydrobenzofuran-5-yl)sulfonyl]guanidino\}pentan-2-yl)asparaginate (4c)

In a $100 \mathrm{~mL}$ round-bottomed flask, compound 3c (664 mg, 1.46 $\mathrm{mmol}$ ) was dissolved in DMF ( $8.8 \mathrm{~mL})$. In another small pear-shaped flask, Fmoc-Asp-OAll (607.8 mg, $1.54 \mathrm{mmol}, 1.05$ equiv) was dissolved in 0.4 M HATU in DMF (3.8 mL, $1.54 \mathrm{mmol}, 1.05$ equiv). Then, DIPEA ( $524 \mu \mathrm{L}, 3.07 \mathrm{mmol}, 2.1$ equiv) was added, and the flask was shaken for 2 min. Afterwards, the content of the pear-shaped flask was transferred to the $100 \mathrm{~mL}$ flask and the resulting solution was stirred overnight. Finally, the reaction mixture was poured into $1 \mathrm{M}$ aq $\mathrm{HCl}(20 \mathrm{~mL})$ and extracted with $\mathrm{CH}_{2} \mathrm{Cl}_{2}(3 \times 40 \mathrm{~mL})$. The organic layers were combined, dried $\left(\mathrm{MgSO}_{4}\right)$, and evaporated in vacuo. The remaining DMF was removed using high vacuum $\left(10^{-2} \mathrm{mbar}\right)$. The crude reaction mixture was then purified by $\mathrm{FC}\left(\mathrm{CH}_{2} \mathrm{Cl}_{2}-\mathrm{MeOH}\right.$, gradient 100:0 to 95:5). The fractions containing the product (TLC analysis) were combined and evaporated in vacuo. Further purification via FC $\left(\mathrm{CH}_{2} \mathrm{Cl}_{2}-\mathrm{MeOH}, 96: 4\right)$ and TLC analysis of the collected fractions gave, after evaporation, compound $\mathbf{4 c}$ in $77 \%$ yield $(938 \mathrm{mg}, 1.13$ $\mathrm{mmol})$ as a colorless solid; $R_{f}=0.30\left(\mathrm{MeOH}-\mathrm{CH}_{2} \mathrm{Cl}_{2}, 5: 95\right)$.

${ }^{1} \mathrm{H} \mathrm{NMR}\left(400 \mathrm{MHz}, \mathrm{CDCl}_{3}\right): \delta=7.76\left(\mathrm{~d}, J=7.6 \mathrm{~Hz}, 2 \mathrm{H}, \mathrm{Fmoc} \mathrm{CH}_{\mathrm{AR}}\right)$, $7.60\left(\mathrm{t}, J=6.2 \mathrm{~Hz}, 2 \mathrm{H}, \mathrm{Fmoc} \mathrm{CH}_{\mathrm{AR}}\right), 7.40\left(\mathrm{t}, J=7.5 \mathrm{~Hz}, 2 \mathrm{H},\left(\mathrm{Fmoc} \mathrm{CH}_{\mathrm{AR}}\right)\right.$, $7.30\left(\mathrm{t}, J=7.5 \mathrm{~Hz}, 2 \mathrm{H}\right.$, Fmoc $\left.\mathrm{CH}_{\mathrm{AR}}\right), 7.22(\mathrm{~d}, J=7.0 \mathrm{~Hz}, 1 \mathrm{H}$, amide $\mathrm{NH})$, $6.58(\mathrm{~s}, 3 \mathrm{H}$, Gua NH), $5.94(\mathrm{~d}, J=7.3 \mathrm{~Hz}, 1 \mathrm{H}$, amide $\mathrm{NH}), 5.85(\mathrm{td}, J=$ $10.8,5.2 \mathrm{~Hz}, 1 \mathrm{H}$, allyl C=CH), $5.29\left(\mathrm{~d}, J=17.1 \mathrm{~Hz}, 1 \mathrm{H}\right.$, allyl $\left.\mathrm{C}=\mathrm{CH}_{2}\right)$, $5.23(\mathrm{~d}, J=10.5 \mathrm{~Hz}, 1 \mathrm{H}$, allyl C=CH$), 4.80(\mathrm{t}, J=7.9 \mathrm{~Hz}, 1 \mathrm{H}, \alpha \mathrm{CH})$, 4.73-4.65 (m, $1 \mathrm{H}, \alpha \mathrm{CH}), 4.65-4.53\left(\mathrm{~m}, 2 \mathrm{H}\right.$, allyl $\left.\mathrm{CH}_{2}\right), 4.48-4.16(\mathrm{~m}$ ovlp, $3 \mathrm{H}$, Fmoc $\left.\mathrm{CH}+\mathrm{Fmoc} \mathrm{CH}_{2}\right), 3.36\left(\mathrm{~d}, J=154.1 \mathrm{~Hz}, 2 \mathrm{H}, \operatorname{Arg} \mathrm{CH}_{2}\right)$, $3.02\left(\mathrm{~s}, 3 \mathrm{H}, \mathrm{NCH}_{3}\right), 2.96\left(\mathrm{~s}, 3 \mathrm{H}, \mathrm{NCH}_{3}\right), 2.95\left(\mathrm{~s}, 2 \mathrm{H}, \mathrm{Pbf} \mathrm{CH}_{2}\right), 3.14-$ $2.80\left(\mathrm{~m}, 2 \mathrm{H}, \operatorname{Asp~} \mathrm{CH}_{2}\right), 2.55\left(\mathrm{~s}, 3 \mathrm{H}, \mathrm{Pbf} \mathrm{CH}_{3}\right), 2.51\left(\mathrm{~s}, 3 \mathrm{H}, \mathrm{Pbf} \mathrm{CH}_{3}\right)$, $2.09\left(\mathrm{~s}, 3 \mathrm{H}, \mathrm{Pbf} \mathrm{CH}_{3}\right), 1.64$ (ddd ovlp, $J=24.2,18.0,11.3 \mathrm{~Hz}, 4 \mathrm{H}, 2 \times$ $\left.\operatorname{Arg} \mathrm{CH}_{2}\right), 1.46\left(\mathrm{~s}, 6 \mathrm{H}, 2 \times \mathrm{Pbf} \mathrm{CH}_{3}\right)$.

${ }^{13} \mathrm{C}$ NMR (101 MHz, $\left.\mathrm{CDCl}_{3}\right): \delta=171.07$ ( $\mathrm{C}=\mathrm{O}$ amide), $170.94(\mathrm{C}=\mathrm{O}$ $\mathrm{NMe}_{2}$ amide), 170.76 ( $\mathrm{C}=\mathrm{O}$ allyl ester), 160.84 ( $\mathrm{Pbf}{ }_{\mathrm{AR}} \mathrm{C}-\mathrm{O}$ ), 156.09 (Fmoc C=O), 153.83 (Gua C=N), 143.79 (Fmoc $\left.{ }_{A R} C=C\right), 141.29$ (Fmoc ${ }_{A R} \mathrm{C}=\mathrm{C}$ ), 140.64 (Pbf ${ }_{A R} \mathrm{C}=\mathrm{C}$ ), 134.89 (Pbf ${ }_{A R} \mathrm{C}=\mathrm{C}$ ), 131.24 (allyl $\mathrm{C}=\mathrm{C}$ ), 127.76 (Fmoc $\left.{ }_{A R} \mathrm{C}=\mathrm{C}\right), 127.29\left(\mathrm{Pbf}_{\mathrm{AR}} \mathrm{C}=\mathrm{C}\right), 127.10\left(\mathrm{Fmoc}_{\mathrm{AR}} \mathrm{C}=\mathrm{C}\right), 125.64$ $\left(\mathrm{Pbf}{ }_{\mathrm{AR}} \mathrm{C}=\mathrm{C}\right), 125.18\left(\mathrm{FmoC}_{\mathrm{AR}} \mathrm{C}=\mathrm{C}\right), 120.00\left(\mathrm{Fmoc}_{\mathrm{AR}} \mathrm{C}=\mathrm{C}\right), 119.02$ (allyl $\mathrm{C}=\mathrm{C}), 118.53\left(\mathrm{Pbf}_{\mathrm{AR}} \mathrm{C}=\mathrm{C}\right), 87.38\left(\mathrm{Pbf} \mathrm{C}_{\mathrm{q}}\right), 67.36\left(\mathrm{Fmoc} \mathrm{CH}_{2}\right), 66.43$ (allyl $\left.\mathrm{CH}_{2}\right), 50.66(\alpha \mathrm{CH}), 48.12(\alpha \mathrm{CH}), 47.09(\mathrm{Fmoc} \mathrm{CH}), 42.97\left(\mathrm{Pbf} \mathrm{CH}_{2}\right)$, $40.66\left(\operatorname{Arg} \mathrm{CH}_{2}\right), 37.80\left(\right.$ Asp $\left.\mathrm{CH}_{2}\right), 37.00\left(\mathrm{NCH}_{3}\right), 36.02\left(\mathrm{NCH}_{3}\right), 30.45$ $\left(\operatorname{Arg} \mathrm{CH}_{2}\right), 28.56\left(\mathrm{Pbf} \mathrm{CH}_{3}\right), 24.08(\operatorname{Arg~CH}), 19.27\left(\mathrm{Pbf} \mathrm{CH}_{3}\right), 17.65(\mathrm{Pbf}$ $\left.\mathrm{CH}_{3}\right), 12.47$ ( $\left.\mathrm{Pbf} \mathrm{CH}_{3}\right)$; (TFA traces).

LCMS (ESI): $m / z=833.5(100 \%)[\mathrm{M}+\mathrm{H}]^{+} ; t_{\mathrm{R}}=1.64 \mathrm{~min}$.

HRMS (ESI): $m / z[\mathrm{M}+\mathrm{H}]^{+}$calcd for $\mathrm{C}_{43} \mathrm{H}_{55} \mathrm{~N}_{6} \mathrm{O}_{9} \mathrm{~S}: 831.3746$; found: 831.3731 .

$N^{2}$-\{[(9H-Fluoren-9-yl)methoxy]carbonyl $\}-N^{4}$-(1-(dimethylamino)-1-oxo-5-\{3-[(2,2,4,6,7-pentamethyl-2,3-dihydrobenzofuran5-yl)sulfonyl]guanidino\}pentan-2-yl)asparagine (7)

In a $100 \mathrm{~mL}$ round-bottomed flask under $\mathrm{N}_{2}$, compound $4 \mathrm{c}(882 \mathrm{mg}$, $1.06 \mathrm{mmol})$ was dissolved in $\mathrm{CH}_{2} \mathrm{Cl}_{2}(10 \mathrm{~mL})$ and $\mathrm{N}_{2}$ was bubbled through the solution for $10 \mathrm{~min}$. Then, $\mathrm{Pd}\left(\mathrm{PPh}_{3}\right)_{4}$ was added (126.9 $\mathrm{mg}, 109.8 \mu \mathrm{mol}, 0.1$ equiv) and again $\mathrm{N}_{2}$ was bubbled through the mixture for $2 \mathrm{~min}$. Afterwards, $\mathrm{PhSiH}_{3}(2.8 \mathrm{~mL})$ was added and the reaction mixture was stirred for $2 \mathrm{~h}$. Finally, the mixture was poured into $1 \mathrm{M}$ aq $\mathrm{HCl}(20 \mathrm{~mL})$ and extracted with $\mathrm{CH}_{2} \mathrm{Cl}_{2}(3 \times 40 \mathrm{~mL})$. The organic layers were combined and dried $\left(\mathrm{MgSO}_{4}\right)$ before being evaporated in vacuo. Compound $\mathbf{7}$ was isolated via semi-preparative HPLC with 3 injections and gradient 2 in $61 \%$ yield ( $510 \mathrm{mg}, 0.64 \mathrm{mmol}$ ) as a colorless powder; $\mathrm{mp} 145^{\circ} \mathrm{C}$. 
IR (neat): 3330 (w), 2971 (w), 2934 (w), $1719(\mathrm{~m}), 1667$ (m), 1627 (s), $1576(\mathrm{~m}), 1549(\mathrm{~m}), 1450(\mathrm{~m}) 1408(\mathrm{~m}), 1372(\mathrm{w}), 1332(\mathrm{w}), 1292$ (m), $1254(\mathrm{~m}), 1202(\mathrm{~m}), 1165(\mathrm{~m}), 1135(\mathrm{~s}), 1090(\mathrm{~s}), 1059(\mathrm{~m}), 996$ (m), $850(\mathrm{~m}), 782(\mathrm{~m}), 760(\mathrm{~m}), 741(\mathrm{~s}), 700(\mathrm{~m}), 641(\mathrm{~s}), 620(\mathrm{~m}) \mathrm{cm}^{-1}$. ${ }^{1} \mathrm{H}$ NMR $\left(400 \mathrm{MHz}\right.$, DMSO- $\left.d_{6}\right): \delta=8.13(\mathrm{~d}, J=8.2 \mathrm{~Hz}, 1 \mathrm{H}$, amide $\mathrm{NH})$, $7.88\left(\mathrm{~d}, J=7.6 \mathrm{~Hz}, 2 \mathrm{H}, \mathrm{Fmoc} \mathrm{CH}_{\mathrm{AR}}\right), 7.70\left(\mathrm{~d}, J=7.4 \mathrm{~Hz}, 2 \mathrm{H}, \mathrm{Fmoc} \mathrm{CH}_{\mathrm{AR}}\right.$ ), $7.50(\mathrm{~d}, J=8.4 \mathrm{~Hz}, 1 \mathrm{H}$, amide $\mathrm{NH}), 7.41(\mathrm{td}, J=7.5,1.1 \mathrm{~Hz}, 2 \mathrm{H}$, Fmoc $\left.\mathrm{CH}_{\mathrm{AR}}\right), 7.32\left(\mathrm{dt}, J=7.5,1.5 \mathrm{~Hz}, 2 \mathrm{H}, \mathrm{Fmoc} \mathrm{CH}_{\mathrm{AR}}\right), 6.64(\mathrm{~s}, 1 \mathrm{H}, \mathrm{Gua} \mathrm{NH})$, $6.40(\mathrm{~s}, 1 \mathrm{H}$, Gua NH), $4.65(\mathrm{q}, J=7.9 \mathrm{~Hz}, 1 \mathrm{H}, \mathrm{Fmoc} \mathrm{CH}), 4.34(\mathrm{td}, J=$ 8.1, $5.5 \mathrm{~Hz}, 1 \mathrm{H}, \alpha \mathrm{CH}$ ), 4.30-4.15 (m ovlp, $3 \mathrm{H}, \mathrm{Fmoc} \mathrm{CH}_{2}+\alpha \mathrm{CH}$ ), 3.06-2.97 (m, $\left.2 \mathrm{H}, \operatorname{Arg} \mathrm{CH}_{2}\right), 2.95\left(\mathrm{~s}, 3 \mathrm{H}_{\mathrm{NCH}}\right), 2.93\left(\mathrm{~s}, 2 \mathrm{H}, \mathrm{Pbf} \mathrm{CH}_{2}\right)$, $2.80\left(\mathrm{~s}, 3 \mathrm{H}, \mathrm{NCH}_{3}\right), 2.56$ (dd, $\left.J=17.0,6.6 \mathrm{~Hz}, 2 \mathrm{H}, \mathrm{Asp} \mathrm{CH}_{2}\right), 2.46(\mathrm{~s}, 3$ $\left.\mathrm{H}, \mathrm{Pbf} \mathrm{CH}_{3}\right), 2.41\left(\mathrm{~s}, 3 \mathrm{H}, \mathrm{Pbf} \mathrm{CH}_{3}\right), 1.99\left(\mathrm{~s}, 3 \mathrm{H}, \mathrm{Pbf} \mathrm{CH} \mathrm{CH}_{3}\right), 1.66-1.50(\mathrm{~m}$, $\left.2 \mathrm{H}, \operatorname{Arg} \mathrm{CH}_{2}\right), 1.39\left(\mathrm{~s}, 6 \mathrm{H}, 2 \times \mathrm{Pbf} \mathrm{CH}_{3}\right), 1.48-1.25\left(\mathrm{~m}, 2 \mathrm{H}, \operatorname{Arg~} \mathrm{CH}_{2}\right)$.

${ }^{13} \mathrm{C}$ NMR (101 MHz, DMSO- $\left.d_{6}\right): \delta=172.99$ ( $\mathrm{C}=\mathrm{O}$ amide), 170.88 ( $\mathrm{C}=\mathrm{O}$ $\mathrm{NMe}_{2}$ amide), $168.73\left(\mathrm{CO}_{2} \mathrm{H}\right), 157.42\left(\mathrm{Pbf}_{\mathrm{AR}} \mathrm{C}-\mathrm{O}\right), 156.03$ (Fmoc $\mathrm{C}=\mathrm{O}$ ), 155.77 (Gua C=N), $143.78\left(\right.$ Fmoc $\left._{A R} \mathrm{C}=\mathrm{C}\right), 143.75\left(\mathrm{Fmoc}_{\mathrm{AR}} \mathrm{C}=\mathrm{C}\right), 140.69$ (Fmoc $\left.{ }_{A R} \mathrm{C}=\mathrm{C}\right), 137.25\left(\mathrm{Pbf}{ }_{\mathrm{AR}} \mathrm{C}=\mathrm{C}\right), 134.14\left(\mathrm{Pbf}{ }_{\mathrm{AR}} \mathrm{C}=\mathrm{C}\right), 131.42(\mathrm{Pbf}$ $\left.{ }_{A R} \mathrm{C}=\mathrm{C}\right), 127.62$ (Fmoc $\left.{ }_{A R} \mathrm{C}=\mathrm{C}\right), 127.06\left(\mathrm{Fmoc}{ }_{A R} \mathrm{C}=\mathrm{C}\right.$ ), 125.24 (FmoC $\left.{ }_{A R} \mathrm{C}=\mathrm{C}\right), 124.31\left(\mathrm{Pbf}_{\mathrm{AR}} \mathrm{C}=\mathrm{C}\right), 120.09\left(\mathrm{FmoC}{ }_{A R} \mathrm{C}=\mathrm{C}\right), 116.24\left(\mathrm{Pbf}{ }_{A R} \mathrm{C}=\mathrm{C}\right)$, $86.28\left(\mathrm{Pbf} \mathrm{C}_{\mathrm{q}}\right), 65.72\left(\right.$ Fmoc $\left.\mathrm{CH}_{2}\right), 50.67(\alpha \mathrm{CH}), 48.04($ Fmoc $\mathrm{CH})$, $46.58(\alpha \mathrm{CH}), 42.44(\mathrm{Pbf} \mathrm{CH}), 39.73\left(\mathrm{Arg} \mathrm{CH}_{2}\right.$ ovlp with DMSO signal), $36.75\left(\right.$ Asp $\left.\mathrm{CH}_{2}\right), 36.50\left(\mathrm{NCH}_{3}\right), 35.16\left(\mathrm{NCH}_{3}\right), 28.95\left(\mathrm{Arg} \mathrm{CH}_{2}\right), 28.28$ $\left(\mathrm{Pbf} \mathrm{CH}_{3}\right), 25.09(\mathrm{Arg} \mathrm{CH}), 18.94\left(\mathrm{Pbf} \mathrm{CH}_{3}\right), 17.58\left(\mathrm{Pbf} \mathrm{CH}_{3}\right), 12.26(\mathrm{Pbf}$ $\left.\mathrm{CH}_{3}\right)$.

LCMS (ESI): $m / z=791.9(100 \%)[\mathrm{M}+\mathrm{H}]^{+} ; t_{\mathrm{R}}=1.61 \mathrm{~min}$.

HRMS (ESI): $m / z[\mathrm{M}+\mathrm{H}]^{+}$calcd for $\mathrm{C}_{40} \mathrm{H}_{51} \mathrm{~N}_{6} \mathrm{O}_{9} \mathrm{~S}: 791.3433$; found: 791.3416.

\section{Preparation of the Octamers 8-10}

\section{Solid-State Peptide Synthesis; General Procedure (GP1)}

All cyanophycin octamer derivatives were synthesized using the following protocol on a $0.03 \mathrm{mmol}$ scale (building block $\mathbf{5}$ for $\mathbf{8 a , b} ; \mathbf{6}$ for 9a,b; and $\mathbf{7}$ for $\mathbf{1 0 a}, \mathbf{b})$.

In a $15 \mathrm{~mL}$ reaction vessel equipped with a valve and attached to a suction system, ca. $107 \mathrm{mg}$ of dry PAL resin $(0.28 \mathrm{mmol} / \mathrm{g})$ was shaken in DMF $(5 \mathrm{~mL})$ for $30 \mathrm{~min}$. Then, the resin was treated with piperidine-DMF $(1: 4,5 \mathrm{~mL})$ for $5 \mathrm{~min}$ and washed $5 \times 1 \mathrm{~min}$ with $\mathrm{DMF}(5$ $\mathrm{mL}$ each).

In a $4 \mathrm{~mL}$ activation vessel, the building block (first coupling: 5: 73.8 mg, 6: $70.0 \mathrm{mg}, 7: 71.1 \mathrm{mg}, 90 \mu \mathrm{mol}, 3$ equiv; further couplings: 5: $49.2 \mathrm{mg}, 6$ : $46.7 \mathrm{mg}, 7: 47.4 \mathrm{mg}, 60 \mu \mathrm{mol}, 2$ equiv) was dissolved in 0.4 M HATU in DMF (first coupling: $210 \mu \mathrm{L}, 84 \mu \mathrm{mol}, 2.8$ equiv; further couplings: $140 \mu \mathrm{L}, 56 \mu \mathrm{mol}, 1.9$ equiv) and then activated DIPEA (first coupling: $27.6 \mu \mathrm{L}, 162 \mu \mathrm{mol}, 5.6$ equiv; further couplings: 18.4 $\mu \mathrm{L}, 108 \mu \mathrm{mol}, 3.8$ equiv) in $\operatorname{DMF}(600 \mu \mathrm{L})$ for $3 \mathrm{~min}$. The activated mixture was transferred to the reaction vessel and the activation vessel rinsed with DMF $(600 \mu \mathrm{L})$. The solution was shaken $4 \mathrm{~h}$ for the first coupling and $2 \mathrm{~h}$ for each of the 7 others with the corresponding building block. Then, the reaction vessel was washed $5 \times 1$ min with DMF ( $5 \mathrm{~mL}$ each). The Fmoc protecting group was removed by 3 treatments ( $2 \mathrm{~min}, 8 \mathrm{~min}, 8 \mathrm{~min}$ ) with piperidine-DMF (1:4, $5 \mathrm{~mL}$ each). The resin was then washed $5 \times 1 \mathrm{~min}$ with $\operatorname{DMF}$ ( $5 \mathrm{~mL}$ each) prior to the next coupling. The resin could then be stored for a few days at $4{ }^{\circ} \mathrm{C}$ in a sealed reaction vessel before cleavage (to give $\mathbf{8 a}, \mathbf{9 a}$, and $\mathbf{1 0 a}$ ) (see GP2, vide infra) or FAM coupling (to give $\mathbf{8 b}, \mathbf{9 b}$, and $\mathbf{1 0 b}$ ) (see FAM coupling procedure, vide infra).

\section{General Cleavage Procedure (GP2)}

This procedure describes the cleavage from the resin for peptides $\mathbf{8}$ 10. After the last coupling, the Fmoc group was removed by using the same procedure as described in GP1. The resin was then washed $5 \times$ $1 \mathrm{~min}$ with DMF (5 mL each) and then $5 \times 1$ min with $\mathrm{CH}_{2} \mathrm{Cl}_{2}(5 \mathrm{~mL}$ each). Finally, the resin was dried by suction for approximately 25 min.

The dry resin was transferred to a tared $100 \mathrm{~mL}$ round-bottomed flask and weighed. Per $\mathrm{g}$ of dried resin, $50 \mathrm{~mL}$ of cleavage cocktail was added $\left\{\mathrm{R}-[\operatorname{Adp}(\mathrm{OH})]_{8}-\mathrm{NH}_{2} \quad(\mathbf{8}): \quad\right.$ TFA-TIS- $\mathrm{H}_{2} \mathrm{O} \quad 95: 2.5: 2.5, \quad \mathrm{R}-$ $[\mathrm{Adp}(\mathrm{OMe})]_{8}-\mathrm{NH}_{2}(\mathbf{9})$, and R-[Adp $\left.\left(\mathrm{NMe}_{2}\right)\right]_{8}-\mathrm{NH}_{2}(\mathbf{1 0})$ : TFA-TIS-MeOH $95: 2.5: 2.5)$ \} and the reaction mixture was stirred at r.t. under $\mathrm{N}_{2}$ for 4 h.

Afterwards, the resin was filtered off using a fritted glass filter and washed with neat TFA. The TFA was evaporated with $\mathrm{N}_{2}$ flow until some material started to precipitate. Then, ice cold $\mathrm{Et}_{2} \mathrm{O}$ was added and the resulting suspension was filtered on Celite and rinsed with ice cold $\mathrm{Et}_{2} \mathrm{O}$ to remove cleaved protecting groups. To solubilize the peptidic material, the Celite was resuspended $3 \times$ in $\mathrm{H}_{2} \mathrm{O}-\mathrm{MeCN}+$ $0.1 \%$ TFA (40 mL each, 1:1) and filtered. The filtrate was frozen, lyophilized, and stored at $4{ }^{\circ} \mathrm{C}$ before purification via semi-preparative HPLC (gradient 1). All HPLC fractions were analyzed by analytical HPLC, combined according to purity (all samples considered $>95 \%$ pure), and lyophilized to yield the TFA salt form of the peptides. Peptides 8a, 9a, and 10a were obtained as colorless powders (5-15 mg each; hygroscopic). The TFA content of the salt was determined by elemental analysis of 8a, according to which 9 TFA molecules were associated with the peptide. We assumed that this was also the case for 9a and 10a. For a typical desalting procedure, vide infra.

\section{$8 a$}

HPLC: $t_{\mathrm{R}}=6.6 \mathrm{~min}$.

MS (MALDI): $m / z(\%)=2189.444(100 \%)[\mathrm{M}+\mathrm{H}]^{+}$.

HRMS (MALDI): $m / z[\mathrm{M}+\mathrm{H}]^{+}$cald for $\mathrm{C}_{80} \mathrm{H}_{156} \mathrm{~N}_{41} \mathrm{O}_{32}: 2187.0588$; found: 2187.0838 .

Anal. Calcd for $\mathrm{C}_{98} \mathrm{H}_{148} \mathrm{~F}_{27} \mathrm{~N}_{40} \mathrm{O}_{50}$ (hygroscopic!): C, 39.79; H, 4.66; F, 16.03; N, 17.51; O, 25.00. Found: C, 36.04; H, 4.95; F, 14.79; N, 17.18.

\section{9a}

HPLC: $t_{\mathrm{R}}=7.8 \mathrm{~min}$.

MS (MALDI): $m / z=2298.692(100 \%)[\mathrm{M}+\mathrm{H}]^{+}$.

HRMS (MALDI): $m / z[\mathrm{M}+\mathrm{H}]^{+}$cald for $\mathrm{C}_{88} \mathrm{H}_{156} \mathrm{~N}_{41} \mathrm{O}_{32}$ : 2299.1835; found: 2299.1837 .

10a

HPLC: $t_{\mathrm{R}}=7.2 \mathrm{~min}$.

MS (MALDI): $m / z=2403.347(100 \%)[\mathrm{M}+\mathrm{H}]^{+}$.

HRMS (MALDI): $m / z[\mathrm{M}+\mathrm{H}]^{+}$cald for $\mathrm{C}_{96} \mathrm{H}_{180} \mathrm{~N}_{49} \mathrm{O}_{24}: 2403.4371$; found: 2403.4381 .

\section{FAM Coupling Procedure (Peptides 8b, 9b, 10b)}

All FAM couplings were performed on a $0.015 \mathrm{mmol}$ scale.

The Fmoc-peptide-resin $(0.015 \mathrm{mmol})$ stored in the reaction vessel was resuspended $10 \mathrm{~min}$ in DMF $(5 \mathrm{~mL})$ and treated $3 \times(2 \mathrm{~min}, 8 \mathrm{~min}$, $8 \mathrm{~min}$ ) with piperidine-DMF (1:4, $5 \mathrm{~mL}$ each). The reaction vessel was then washed $5 \times 1 \mathrm{~min}$ with $\mathrm{DMF}(5 \mathrm{~mL}$ each). Then, in an activation vessel 5/6-FAM (33.9 $\mathrm{mg}, 0.09 \mathrm{mmol}, 6$ equiv) was predissolved in DMF $(5 \mathrm{~mL})$. To this solution, 0.4 M HATU in DMF $(215 \mu \mathrm{L}, 0.086$ mmol, 5.7 equiv) and DIPEA ( $31.4 \mu \mathrm{L}, 0.18 \mathrm{mmol}, 12$ equiv) were add- 
ed and the mixture was shaken for $10 \mathrm{~min}$. The content of the activation vessel was then transferred to the reaction vessel and shaken overnight $(16 \mathrm{~h})$. The resin was then washed $5 \times 1 \mathrm{~min}$ with DMF $(5$ $\mathrm{mL}$ each) and treated with piperidine-DMF (1:4, $5 \mathrm{~mL}$ ) for $30 \mathrm{~min}$. After this step, resin-bound $\mathbf{8 b}, \mathbf{9 b}$, and $\mathbf{1 0 b}$ were submitted to cleavage following GP2. The TFA salts of the FAM derivatives $\mathbf{8 b}, \mathbf{9 b}$, and $\mathbf{1 0 b}$ were obtained as yellow powders (2-3 mg each; hygroscopic).

\section{8b}

HPLC: $t_{\mathrm{R}}=8.4 \mathrm{~min}$.

MS (MALDI): $m / z=2548.919(100 \%)[\mathrm{M}+\mathrm{H}]^{+}$.

\section{9b}

HPLC: $t_{\mathrm{R}}=9.8 \mathrm{~min}$.

MS (MALDI): $m / z=2657.685(100 \%)[\mathrm{M}+\mathrm{H}]^{+}$.

\section{0b}

HPLC: $t_{\mathrm{R} 1}=9.1 \mathrm{~min}, t_{\mathrm{R} 2}=9.2 \mathrm{~min}$.

MS (MALDI): $m / z=2761.782(100 \%)[\mathrm{M}+\mathrm{H}]^{+}$.

Note: For FAM- $[\operatorname{Adp}(\mathrm{OH})]_{8}-\mathrm{NH}_{2}(\mathbf{8 b})$ and FAM- $[\mathrm{Adp}(\mathrm{OMe})]_{8}-\mathrm{NH}_{2}(\mathbf{9 b})$, one consitutional isomer of the FAM labeled peptide could be isolated by semi-preparative HPLC (5-FAM or 6-FAM). In the case of FAM$\left[\mathrm{Adp}\left(\mathrm{NMe}_{2}\right)\right]_{8}-\mathrm{NH}_{2}(\mathbf{1 0 b})$, only a mixture of the 2 isomers (5/6-FAM) could be isolated in pure form (see Figure 3 ).

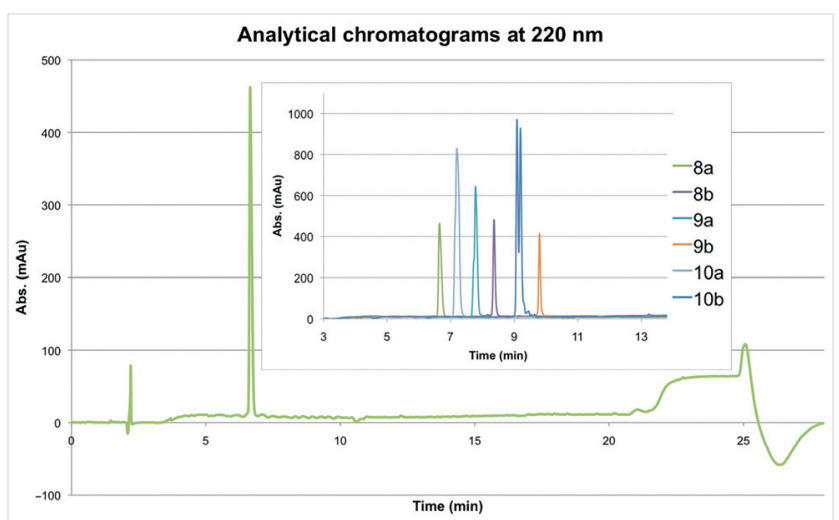

Figure 3 Analytical chromatograms at $220 \mathrm{~nm}$ of the isolated peptides 8-10. The two peaks for $\mathbf{1 0 b}$ are due to separation of the two constitutional isomers with 5/6-FAM groups; in the other cases these isomers are not separated.

\section{Desalting the Octapeptides; Typical Procedure}

\section{Desalting of 8a}

In a $50 \mathrm{~mL}$ falcon tube, a solution of $\mathbf{8 a}$ in $\mathrm{H}_{2} \mathrm{O}(5 \mathrm{~mL}$, double deionized) was incubated at r.t. for $10 \mathrm{~min}$ with Amberlyst A26 (HO form, $1.5 \mathrm{~g}$ ). The mixture was then transferred to a fritted glass filter and washed 5 times with $\mathrm{H}_{2} \mathrm{O}$ (each $20 \mathrm{~mL}$, double deionized). The filtrate was collected, frozen, and lyophilized in order to give desalted 8a. For control of fluorine content a ${ }^{19} \mathrm{~F}$ NMR spectrum was recorded; there was only a tiny little signal from TFA $(\delta=-75.60)$.

\section{References}

(1) Frankel, A. D.; Pabo, C. O. Cell 1988, 55, 1189.

(2) Derossi, A. H.; Joliot, A. H.; Chassaing, G.; Prochiantz, A. J. Biol. Chem. 1994, 269, 10444.

(3) (a) Wender, P. A.; Mitchell, D. J.; Pattabiraman, K.; Pelkey, E. T.; Steinman, L.; Rothbard, J. B. Proc. Natl. Acad. Sci. U S A 2000, 97, 13003. (b) Geihe Stanzl, E.; Trantow, B. M.; Vargas, J. R.; Wender, P. A. Acc. Chem. Res. 2013, 46, 2944.

(4) (a) Futaki, S.; Suzuki, T.; Ohashi, W.; Yagami, T.; Tanaka, S.; Ueda, K.; Sugiura, Y. J. Biol. Chem. 2001, 276, 5836. (b) Futaki, S.; Nakase, I. Acc. Chem. Res. 2017, 50, 2449.

(5) Copolovici, D. M.; Langel, K.; Eriste, E.; Langel, Ü. ACS Nano 2014, 8, 1972.

(6) Grogg M.; Hilvert D.; Ebert M.-O.; Beck A. K.; Seebach D.; Kurth F.; Dittrich P. S.; Sparr C.; Wittlin S.; Rottmann M.; Mäser P. Helv. Chim. Acta 2018, 15, DOI: 10.1002/hlca.201800112.

(7) Simon, R. D. Proc. Natl. Acad. Sci. U S A 1971, 68, 265.

(8) Frommeyer, M.; Wiefel, L.; Steinbüchel, A. Crit. Rev. Biotechnol. 2016, 36, 153; and references cited therein.

(9) (a) Sallam, A.; Kast, A.; Przybilla, S.; Meiswinkel, T.; Steinbüchel, A. Appl. Environ. Microbiol. 2009, 75, 29; and earlier references cited therein. (b) Krehenbrink, M.; Sallam, A.; Steinbüchel, A. Biotechnical Approaches to Dipeptide Production, In Industrial Biocatalysis; Grunwald, P., Ed.; Pan Stanford Publishing Pte. Ltd: Singapore, 2015, Chap. 2 ; and earlier references cited therein.

(10) Seebach, D.; Beck, A. K.; Bierbaum, D. J. Chem. Biodiv. 2004, 1, 1111.

(11) Kolesinska, B.; Wasko, J.; Kaminski, Z.; Geueke, B.; Kohler, H.-P. E.; Seebach, D. Helv. Chim. Acta 2018, 101, e1700259.

(12) Heck, T.; Limbach, M.; Geueke, B.; Zachariasc, M.; Gardiner, J.; Kohler, H.-P. E.; Seebach, D. Chem. Biodiv. 2006, 3, 1325.

(13) Albericio, F.; Barany, G. Int. J. Pept. Protein Res. 1987, 30, 206.

(14) Kurth F.; Dittrich P. S.; Walde P. J.; Seebach D. Chem. Biodiv. 2018, DOI: $10.1002 / c b d v .201800302$. 